NCT

Neumología y Cirugía de Tórax

Revisión

Vol. 78 - Núm. 4 / Octubre-Diciembre 2019

dx.doi.org/10.35366/NT194G

\title{
Guía para el tratamiento y seguimiento de los niños de dos meses a 18 años con displasia broncopulmonar
}

\author{
Guidelines for the treatment and follow-up of children \\ aged two months to 18 years with bronchopulmonary \\ dysplasia
}

Alicia Buenrostro Gaitán,* Yerania Sánchez Miranda, Carlos Juárez Ortiz*

*Hospital General Dr. Gaudencio González Garza, Centro Médico Nacional La Raza, Instituto Mexicano del Seguro Social. Ciudad de México.

RESUMEN. La displasia broncopulmonar es una de las complicaciones respiratorias a evaluar en un niño que nace prematuramente y que está inmerso en diferentes comorbilidades, tanto respiratorias como sistémicas que impactan en el desarrollo a lo largo de su vida. Por esta razón, una guía de seguimiento y tratamiento dirigido a prevenir complicaciones y mejorar su calidad de vida es imprescindible para la toma de decisiones de los médicos que tienen a cargo pacientes con esta enfermedad. Esta guía de seguimiento y tratamiento a largo plazo de niños con displasia broncopulmonar contiene información actualizada dirigida al personal de salud con la finalidad de mejorar los procesos de atención y prevención en personas de dos meses a 18 años de edad. Incluye evidencias y recomendaciones acerca de: estudios de imagen, función respiratoria, consumo de líquidos, diuréticos, broncodilatadores, esteroides, oxígeno, hipertensión pulmonar, trastornos del sueño, exacerbaciones, nutrición, comorbilidades y prevención de complicaciones. En México, la incidencia oficial de displasia broncopulmonar es desconocida; sin embargo, se presume en incremento gracias a la supervivencia de estos niños en las terapias intensivas neonatales del país, por lo que lo médicos generales, médicos familiares, rehabilitadores, pediatras y subespecialistas pediatras requieren estar actualizados para el seguimiento coordinado y eficaz de esta población.

Palabras clave: Displasia broncopulmonar, hipertensión pulmonar, seguimiento pulmonar.
ABSTRACT: Bronchopulmonary dysplasia is one of the respiratory complications to be evaluated in a child who is born prematurely and who is immersed in different respiratory and systemic comorbidities that impact development throughout his or her life. For this reason, a follow-up and treatment guide aimed at preventing complications and improving his or her quality of life is essential for the decision making of the doctors in charge of patients with this disease. This guide for long-term follow-up and treatment of children with bronchopulmonary dysplasia contains updated information aimed at health personnel with the aim of improving the processes of care and prevention in people from 2 months to 18 years of age. It includes evidence and recommendations about: image studies, respiratory function, fluid intake, diuretics, bronchodilators, steroids, oxygen, pulmonary hypertension, sleep disorders, exacerbations, nutrition, comorbidities and prevention of complications. In Mexico, the official incidence of Bronchopulmonary Dysplasia is unknown; however, it is presumed to increase thanks to the survival of these children in the country's neonatal intensive therapies, so general practitioners, family doctors, rehabilitators, pediatricians and pediatric subspecialists need to be updated for coordinated and effective monitoring of this population.

Keywords: Bronchopulmonary dysplasia, pulmonary hypertension, pulmonary monitoring.

\section{Correspondencia:}

Dr. Carlos Juárez Ortiz

Hospital General Dr. Gaudencio González Garza, Centro Médico

Nacional La Raza, Instituto Mexicano del Seguro Social.

Correo electrónico: broncoscopiajuarez@gmail.com

Trabajo recibido: 30-IV-2019; aceptado: 03-VII-2019. 
Autores, validación y revisión

\begin{tabular}{|c|c|c|c|c|c|}
\hline \multicolumn{6}{|c|}{ Autores } \\
\hline $\begin{array}{l}\text { Yerania Sánchez } \\
\text { Miranda }\end{array}$ & $\begin{array}{l}\text { Neumología } \\
\text { pediátrica } \\
\text { Alta especialidad en } \\
\text { broncoscopia }\end{array}$ & $\begin{array}{l}\text { IMSS } \\
\text { CMN La Raza } \\
\text { Hospital General } \\
\text { «Dr. Gaudencio } \\
\text { González Garza» }\end{array}$ & $\begin{array}{l}\text { Jacarandas sin } \\
\text { número, Col. La } \\
\text { Raza, Alcaldía } \\
\text { Azcapotzalco. } \\
\text { Ciudad de México }\end{array}$ & Médico no familiar & $\begin{array}{l}\text { Pediatría } \\
\text { Neumología } \\
\text { pediátrica }\end{array}$ \\
\hline \multicolumn{6}{|c|}{ Coordinador metodológico } \\
\hline $\begin{array}{l}\text { María Guadalupe } \\
\text { Casales Hernández }\end{array}$ & $\begin{array}{l}\text { Maestra en } \\
\text { Ciencias } \\
\text { Sociomédicas }\end{array}$ & $\begin{array}{l}\text { Centro Nacional } \\
\text { de Programas } \\
\text { Preventivos } \\
\text { y Control de } \\
\text { Enfermedades. } \\
\text { Secretaría de Salud } \\
\text { Federal }\end{array}$ & $\begin{array}{l}\text { Benjamín Franklin } \\
\text { 132, Col. Escandón, } \\
\text { Alcaldía Miguel } \\
\text { Hidalgo, CP.11800. } \\
\text { Ciudad de México }\end{array}$ & $\begin{array}{l}\text { Coordinadora } \\
\text { de Análisis de la } \\
\text { información en el } \\
\text { Programa de Salud } \\
\text { en el Adulto y en el } \\
\text { Anciano }\end{array}$ & $\begin{array}{l}\text { Sociedad Mexicana } \\
\text { de Salud Pública }\end{array}$ \\
\hline $\begin{array}{l}\text { Calixto Galeana } \\
\text { Miramontes }\end{array}$ & $\begin{array}{l}\text { Neumología } \\
\text { pediátrica }\end{array}$ & $\begin{array}{l}\text { Hospital Naval de } \\
\text { Especialidades } \\
\text { de Veracruz } \\
\text { (HOSNAVESVER) }\end{array}$ & $\begin{array}{l}\text { General Figueroa } \\
151 \text { Centro, } 91700 \\
\text { Veracruz, Veracruz }\end{array}$ & $\begin{array}{l}\text { Adscrito a la } \\
\text { consulta externa de } \\
\text { pediatría }\end{array}$ & $\begin{array}{l}\text { Pediatría } \\
\text { Neumología } \\
\text { pediátrica }\end{array}$ \\
\hline \multicolumn{6}{|c|}{ Validación protocolo de búsqueda } \\
\hline $\begin{array}{l}\text { Enrique Juárez } \\
\text { Sánchez }\end{array}$ & $\begin{array}{l}\text { Maestro en } \\
\text { bibliotecología } \\
\text { y estudios de } \\
\text { información }\end{array}$ & $\begin{array}{l}\text { Hospital General } \\
\text { de México «Dr. } \\
\text { Eduardo Liceaga» }\end{array}$ & $\begin{array}{l}\text { Dr. Balmis 148, Col } \\
\text { Doctores, Alcaldía } \\
\text { Cuauhtémoc. } \\
\text { Ciudad de México }\end{array}$ & $\begin{array}{l}\text { Coordinador } \\
\text { de Servicios de } \\
\text { Información. }\end{array}$ & No aplica \\
\hline
\end{tabular}




\section{CONTENIDO}

Guía para el tratamiento y seguimiento de los niños de 2 meses a 18 años con displasia broncopulmonar

Resumen

1. Clasificación

2. Preguntas a responder

3. Aspectos generales

3.1 Justificación

3.2 Alcance y objetivos

3.3 Definición y diagnóstico

4. Evidencias y recomendaciones

4.1 Tabla de símbolos utilizados en esta Guía

4.2 Escala de gradación o valores de evidencia
5. Anexos

5.1 Estrategia de búsqueda

5.2 Seguimiento del paciente con displasia broncopulmonar

5.3 Cuantificación de líquidos

5.4 Dosis bajas, medias y altas de corticosteroides inhalados en el menor de 5 años

5.5 Diagrama de flujo protocolo retiro de oxígeno

6. Abreviaturas y acrónimos

7. Glosario

Bibliografía

\section{CLASIFICACIÓN}

\begin{tabular}{|c|c|}
\hline Profesionales de la salud & Neumólogo pediatra \\
\hline $\begin{array}{l}\text { Clasificación de la } \\
\text { enfermedad }\end{array}$ & CIE 10: P 27.1 Displasia broncopulmonar originada en el período perinatal \\
\hline $\begin{array}{l}\text { Categoría de guía de } \\
\text { práctica clínica }\end{array}$ & $\begin{array}{l}\text { Primero, segundo y tercer nivel de atención } \\
\text { Tratamiento } \\
\text { Seguimiento }\end{array}$ \\
\hline Usuarios potenciales & Médico general, Médico familiar, Médico pediatra, Neumólogo pediatra, Urgenciólogo pediatra \\
\hline Población blanco & $\begin{array}{l}\text { Niñas y niños de dos meses a } 18 \text { años de edad con diagnóstico de displasia broncopulmonar } \\
\text { Se excluye a los niños nacidos a término, ya que salen fuera de la definición }\end{array}$ \\
\hline $\begin{array}{l}\text { Fuente de } \\
\text { financiamiento/ } \\
\text { patrocinador }\end{array}$ & Recursos propios de los investigadores \\
\hline $\begin{array}{l}\text { Intervenciones y } \\
\text { actividades } \\
\text { consideradas }\end{array}$ & $\begin{array}{l}\text { Exploración física dirigida } \\
\text { Uso de pruebas complementarias para el seguimiento (electrolitos séricos, radiografía de tórax, pruebas de función } \\
\text { pulmonar, ecocardiograma) } \\
\text { Tratamiento (tratamiento nutricional; Fármacos: broncodilatadores inhalados, esteroides inhalados, diuréticos, líquidos } \\
\text { orales. Oxigenoterapia) } \\
\text { Prevención de infecciones respiratorias, medidas no farmacológicas y farmacológicas (inmunización y palivizumab) } \\
\text { Abordaje de comorbilidades y complicaciones } \\
\text { Calendario de citas y seguimiento a largo plazo } \\
\text { Indicadores de referencia a segundo y tercer nivel de atención }\end{array}$ \\
\hline $\begin{array}{l}\text { Impacto esperado en la } \\
\text { salud }\end{array}$ & $\begin{array}{l}\text { Disminución de complicaciones } \\
\text { Disminución de ingresos y días de hospitalización } \\
\text { Disminución de mortalidad } \\
\text { Referencia oportuna } \\
\text { Mejora de la calidad de vida } \\
\text { Mejora en el uso de recursos }\end{array}$ \\
\hline Metodología & $\begin{array}{l}\text { Definición del enfoque de la Guía de Práctica Clínica (GPC) } \\
\text { Elaboración de preguntas clínicas } \\
\text { Protocolo sistematizado de la literatura: Recuperación de guías internacionales, metaanálisis, ensayos clínicos } \\
\text { aleatorizados o revisiones sistemáticas que den respuesta a las preguntas planteadas, de los cuales se seleccionarán } \\
\text { las fuentes con mayor puntaje obtenido en la evaluación de su metodología y las de mayor nivel en cuanto a } \\
\text { gradación de evidencias y recomendaciones de acuerdo con la escala establecida } \\
\text { Respuesta a preguntas clínicas por revisión sistemática de la literatura y gradación de evidencia y recomendaciones } \\
\text { Análisis de evidencias y recomendaciones en el contexto nacional } \\
\text { Emisión de evidencias y recomendaciones } \\
\text { Validación del protocolo de búsqueda }\end{array}$ \\
\hline
\end{tabular}


Neumol Cir Torax. 2019; 78 (4): 371-394

\begin{tabular}{|l|l|}
\hline Método de Integración & Protocolo sistematizado de búsqueda: algoritmo de búsqueda reproducible en bases de datos electrónicas, \\
& Número de fuentes documentales utilizadas: \\
& Total: 36 \\
& Guías seleccionadas: 1 \\
& Revisiones sistemáticas: 4 \\
& Metaanálisis: 2 \\
& Revisiones: 29 \\
\hline Método de validación & Validación externa: por pares a través de instrumento AGREE II \\
\hline Conflicto de intereses & $\begin{array}{l}\text { Todos los miembros del grupo de trabajo han declarado la ausencia de conflictos de interés en relación a la } \\
\text { información, objetivos y propósitos de la presente Guía de Práctica Clínica }\end{array}$ \\
\hline Registro & $\begin{array}{l}\text { Esta guía será adecuada y presentada a la Dirección de Integración de Guías de Práctica Clínica del Centro Nacional } \\
\text { de Excelencia Tecnológica en Salud (CENETEC-Salud), en caso de ser aceptada contará con el registro pertinente } \\
\text { por dicha institución }\end{array}$ \\
\hline Actualización & $\begin{array}{l}\text { Fecha de publicación: } \\
\text { Esta guía será actualizada cuando exista evidencia que así lo determine o de manera programada, a los tres a cinco } \\
\text { años posteriores a la publicación. }\end{array}$ \\
\hline
\end{tabular}

\section{PREGUNTAS A RESPONDER}

1. ¿Cómo se realiza la estadificación de gravedad de los niños con displasia broncopulmonar (DBP)?

2. ¿Cuáles son los factores de riesgo para desarrollar DBP?

3. ¿Cuál es el aporte de líquidos adecuado en niños con DBP moderada y grave para evitar sobrecarga hídrica?

4. ¿Cuál es el tratamiento farmacológico en los niños con DBP?

5. En niños con DBP, el protocolo de retiro de oxígeno domiciliario en comparación con el retiro no supervisado idisminuye el riesgo de HP?

6. ¿Cuáles son las complicaciones y comorbilidades asociadas a DBP?

7. ¿Cuáles son las causas de exacerbación de DBP?

8. ¿Cuál es la cantidad adecuada de calorías que debe recibir un niño con DBP para fomentar un buen estado nutricional?

9. ¿Cuáles son los criterios de referencia para la atención de los niños con DBP en el segundo y tercer nivel de atención?

10. ¿Cuál es el calendario de seguimiento para los niños con DBP?

\section{ASPECTOS GENERALES}

\subsection{Justificación}

En México anualmente nacen más de 120 mil prematuros, de los cuales se estima desarrollaran DBP unos 40 mil. De las complicaciones asociadas a la prematurez, la DBP representa una de las más importantes por su impacto en la salud a largo plazo. La DBP provoca: muerte en el primer año de vida, hospitalización prolongada, incremento en los ingresos hospitalarios por causa respiratoria, diferentes grados de deterioro neurológico, es la principal causa de uso crónico domiciliario de oxígeno en niños y frecuentemente causa falla para crecer.

En nuestro país, existe una guía del Instituto Mexicano del Seguro Social realizada en el año 2015, la cual engloba una revisión actualizada de los cuidados y aspectos neonatales más importantes para el tratamiento de la DBP; su enfoque sólo incluye el manejo del paciente hasta el egreso hospitalario de la unidad de cuidados neonatales y los dos primeros años de vida. Sin embargo, esta enfermedad puede afectar la función pulmonar a lo largo de toda la vida del paciente. La falta de seguimiento predispone a múltiples complicaciones, lo que repercute en su calidad de vida y la de sus familias; representa, además, una carga financiera importante para el sistema de salud nacional, por el costo de sus tratamientos, así como los reingresos hospitalarios.

En los diferentes centros de nuestra nación que atienden niños con DBP existe heterogeneidad en el manejo; esto debido a diversos factores, tales como variabilidad en la definición de DBP, diferente infraestructura y tecnología, controversia y áreas de incertidumbre en el tratamiento.

La DBP es una enfermedad pulmonar crónica que, como consecuencia de múltiples factores, añadidos a la inmadurez de la vía aérea, provoca una disminución del crecimiento pulmonar, no sólo de la vía aérea sino también de los vasos pulmonares, dando lugar a una limitación en la función respiratoria de grado variable. La característica fundamental es la interrupción del crecimiento pulmonar distal, generada por lesiones que ocurren principalmente en las fases canalicular y sacular del desarrollo pulmonar, con diversos grados de alteración en la arquitectura pulmonar debido a disrupción del desarrollo alveolar y vascular, generando un menor número de alvéolos, pero de mayor tamaño, crecimiento vascular anormal e inflamación, manifestándose como reducción en la superficie de intercambio gaseoso, limitación funcional al ejercicio, grados variables de 
obstrucción al flujo aéreo, hipertensión pulmonar y pobre tolerancia a las infecciones respiratorias.

La DBP es una causa importante de disfunción pulmonar a largo plazo. De todas las enfermedades pulmonares obstructivas, la DBP tiene el inicio más temprano. Los lactantes con DBP tienen un desarrollo pulmonar aberrante y pueden experimentar alteraciones de por vida en la función cardiopulmonar.

Los factores implicados en estas alteraciones del desarrollo pulmonar incluyen: pulmones estructural y bioquímicamente inmaduros, infección, inflamación, hiperoxia, lesión oxidativa, lesión mecánica asociada con soporte respiratorio de presión positiva, falta de impulso respiratorio, apnea y mala nutrición. Es probable que las respuestas de los pacientes a estos insultos estén moduladas por factores genéticos, epigenéticos y prenatales y que distintos factores causales dominen en diferentes pacientes.

\section{Epidemiología}

La DBP ocurre en el 20\% de todos los recién nacidos prematuros con ventilación mecánica, aunque existe una gran variabilidad en cuanto a su prevalencia. La mayoría de los casos ocurren en bebés que nacen antes de las 30 semanas de edad gestacional y con peso al nacer menor a 1,200 g.

De acuerdo al estudio de Fanaroff et al. en la cohorte «inborn infants», de 18,153 neonatos de muy bajo peso al nacer la incidencia de DBP por peso fue:

42\% de los niños con peso al nacer 501-750 g

- $25 \%$ de los bebés con peso al nacer 751-1,000 g

- $11 \%$ de los niños con peso al nacer de 1,001 a 1,250 g

- $5 \%$ de los bebés con peso al nacer 1,251-1,500 g

En el estudio del NICHD en Estados Unidos (9575 sujetos), la incidencia de DBP es del $68 \%$ en lactantes de edad gestacional extremadamente baja (nacidos a las 22-28 semanas, media de peso $836 \mathrm{~g}$ ). En estos niños, tanto la mortalidad como la DBP se asociaron inversamente con la edad gestacional al nacer. De acuerdo con la base de datos NIS que examinó más de 9.5 millones de hospitalizaciones neonatales entre 1993 y 2006 reveló que la incidencia de DBP disminuyó $4.3 \%$ por año durante este período. Sin embargo, de acuerdo a la revisión sistemática de Zarqa Ali et al. la supervivencia de los niños prematuros va en incremento y la prevalencia de la DBP está aumentando.

En México, no existe una base de datos nacional y los datos obtenidos por las principales instituciones públicas de salud reflejan un subregistro de esta enfermedad.

\subsection{Alcance y objetivos}

Esta guía aporta las directrices más importantes basadas en la mejor evidencia disponible para el tratamiento y segui- miento a largo plazo de los niños con DBP. Se excluye el manejo perinatal, para lo cual ya existe una guía mexicana.

Las recomendaciones aquí establecidas permiten al médico interesado, tratar y dar seguimiento a los pacientes con DBP, enriqueciendo su conducta médica y conocimientos previos para cubrir las necesidades de atención apoyados con evidencia actualizada.

Esta guía está dirigida a los médicos que dan atención a los niños con DBP, en el primero, segundo y tercer nivel de atención pediátrica, con énfasis en el seguimiento por consulta externa.

\subsubsection{Objetivo general}

- El objetivo de la presente guía es realizar recomendaciones basados en la mejor evidencia científica, con la finalidad de unificar el diagnóstico y tratamiento a largo plazo de los niños con DBP para mejorar su salud.

\subsubsection{Objetivos específicos}

- Reducir la variabilidad existente entre los profesionales de la salud en el diagnóstico, tratamiento y seguimiento a largo plazo de los niños con DBP.

- Establecer un plan de seguimiento a largo plazo de los pacientes con DBP para mejorar su calidad de vida.

- Optimizar los recursos para la atención de los niños con DBP, con la finalidad de otorgar el mejor tratamiento disponible.

- Prevenir las complicaciones asociadas a DBP en los niños de 2 meses a 18 años que la padecen.

- Proporcionar la definición internacionalmente aceptada hasta el momento, para disminuir la variabilidad existente en el equipo de salud.

- Detectar y tratar las complicaciones y comorbilidades de los niños con DBP.

- Disminuir las rehospitalizaciones por causas prevenibles en los niños con DBP.

\subsection{Definición y diagnóstico}

La definición internacionalmente aceptada es la propuesta por Jobe y Bancalari: «Recién nacido pretérmino con necesidad de oxígeno suplementario por al menos 28 días»; y su clasificación en leve, moderada o grave según las necesidades de oxígeno o de soporte ventilatorio (Tabla 1). El momento para llevar a cabo esta clasificación dependerá de las semanas de gestación del recién nacido:

- Para los neonatos prematuros nacidos antes de las 32 semanas de gestación, la estadificación será en el momento en que cumplan 36 semanas de edad gestacional corregidas ( 36 semanas posmenstruales) o al alta, lo que ocurra primero. 
- Para los recién nacidos pretérmino $\geq 32$ semanas, la categorización será a los 56 días de edad postnatal o al alta, lo que ocurra antes.

Tabla 1: Gravedad de la displasia broncopulmonar.

\begin{tabular}{|l|l|}
\hline \multicolumn{1}{|c|}{$\begin{array}{c}\text { Estadio de } \\
\text { severidad }\end{array}$} & \multicolumn{1}{c|}{ Criterio } \\
\hline DBP leve & $\begin{array}{l}\mathrm{SpO}_{2} \text { mayor al 90\% respirando aire } \\
\text { ambiente }\end{array}$ \\
\hline DBP moderada & $\begin{array}{l}\text { Necesidad de oxígeno suplementario } \mathrm{FiO}_{2} \\
\text { menor a 30\% para mantener } \mathrm{SpO}_{2}>90 \%\end{array}$ \\
\hline DBP severa & $\begin{array}{l}\text { Necesidad de oxígeno suplementario } \mathrm{FiO}_{2} \\
\geq 30 \% \text { y/o CPAP o ventilación a presión } \\
\text { positiva }\end{array}$ \\
\hline
\end{tabular}

Adaptado de: Jobe A, Bancalari E. Bronchopulmonary Dysplasia-NICHD/NHLBI/ ORD Workshop Summary. Am J Respir Crit Care Med 2001; 163 (7): 1723-1729.

Un día de tratamiento con oxígeno suplementario se define como 12 horas o más de exposición al oxígeno. Los bebés deben requerir oxígeno suplementario por un acumulo de 28 días o más antes de la evaluación de severidad. Finalmente, el soporte respiratorio en el momento de la evaluación debe reflejar la terapia habitual del niño en los días que rodean la evaluación y no un evento «agudo».

\section{EVIDENCIAS Y RECOMENDACIONES}

\subsection{Tabla de símbolos utilizados en esta Guía}

E EVIDENCIA

R RECOMENDACIÓN

$\checkmark$ PUNTO DE BUENA PRÁCTICA

\subsection{Escala de gradación o valores de evidencia}

La escala modificada de Shekelle, et al.

Clasifica la evidencia en niveles (categorías) e indica el origen de las recomendaciones emitidas por medio del grado de fuerza. Para establecer la categoría de la evidencia utiliza números romanos de I a IV y las letras a y b (minúsculas). En la fuerza de recomendación letras mayúsculas de la $A$ a la D.

\begin{tabular}{|l|l|}
\hline \multicolumn{1}{|c|}{ Categoría de la evidencia } & Fuerza de la recomendación \\
\hline $\begin{array}{l}\text { la. Evidencia para metaanálisis } \\
\text { de los estudios clínicos } \\
\text { aleatorios }\end{array}$ & $\begin{array}{l}\text { A. Directamente basada en } \\
\text { evidencia categoría I }\end{array}$ \\
\hline $\begin{array}{l}\text { Ib. Evidencia de por lo menos } \\
\text { un estudio clínico controlado } \\
\text { aleatorios }\end{array}$ & \\
\hline
\end{tabular}

\begin{tabular}{|c|c|}
\hline $\begin{array}{l}\text { Ila. Evidencia de por lo menos } \\
\text { un estudio controlado sin } \\
\text { aleatoridad }\end{array}$ & \multirow{2}{*}{$\begin{array}{l}\text { B. Directamente basada } \\
\text { en evidencia categoría II o } \\
\text { recomendaciones extrapoladas } \\
\text { de evidencia I }\end{array}$} \\
\hline $\begin{array}{l}\text { Ilb. Al menos otro tipo de } \\
\text { estudio cuasiexperimental o } \\
\text { estudios de cohorte }\end{array}$ & \\
\hline $\begin{array}{l}\text { III. Evidencia de un estudio } \\
\text { descriptivo no experimental, tal } \\
\text { como estudios comparativos, } \\
\text { estudios de correlación, } \\
\text { casos y controles y revisiones } \\
\text { clínicas }\end{array}$ & $\begin{array}{l}\text { C. Directamente basada en } \\
\text { evidencia categoría III o en } \\
\text { recomendaciones extrapoladas } \\
\text { de evidencias categorías I o II }\end{array}$ \\
\hline $\begin{array}{l}\text { IV. Evidencia de comité de } \\
\text { expertos, reportes opiniones } \\
\text { o experiencia clínica de } \\
\text { autoridades en la materia o } \\
\text { ambas }\end{array}$ & $\begin{array}{l}\text { D. Directamente basadas en } \\
\text { evidencia categoría IV o de } \\
\text { recomendaciones extrapoladas } \\
\text { de evidencias categorías II, III }\end{array}$ \\
\hline
\end{tabular}

Modificado de: Shekelle PG, Wolf SH, Eccles M, Grimshaw J. Clinical guidelines: developing guidelines. BMJ 1999;318(7183):593-559.

Factores de riesgo y protectores

\begin{tabular}{|c|c|c|}
\hline \multicolumn{2}{|r|}{ Evidencia/Recomendación } & Nivel/Grado \\
\hline$E$ & $\begin{array}{l}\text { Los factores prenatales que pueden } \\
\text { aumentar el riesgo de DBP son: } \\
\text { sexo masculino, corioamnionitis, } \\
\text { concentraciones elevadas en líquido } \\
\text { amniótico de IL-6, IL-1b, IL-8; factores } \\
\text { genéticos (polimorfismos en el intrón } 4 \\
\text { de SP-B y mutaciones dominantes en } \\
\text { SP-C); restricción del crecimiento fetal y } \\
\text { colonización por ureaplasma }\end{array}$ & $\begin{array}{l}\text { la } \\
\text { Shekelle } \\
\text { DynaMed Plus, } \\
2017\end{array}$ \\
\hline$E$ & $\begin{array}{l}\text { Factores postnatales: toxicidad por } \\
\text { oxígeno y lesión pulmonar inducida por } \\
\text { ventilador (radicales libres de oxígeno, } \\
\text { cascada inflamatoria, volutrauma, } \\
\text { biotrauma, atelectrauma, barotrauma); } \\
\text { sepsis de inicio tardío, ductus arterioso } \\
\text { permeable, concentraciones bajas de } \\
\text { retinol en plasma, reanimación en sala } \\
\text { de parto con FIO mayor al } 30 \% \\
\text { El uso temprano de la ventilación } \\
\text { no invasiva (CPAP), disminuye las } \\
\text { tasas de DBP versus intubación. Los } \\
\text { corticosteroides sistémicos posnatales } \\
\text { y la vitamina A intramuscular reducen } \\
\text { las tasas de DBP en los recién nacidos } \\
\text { prematuros }\end{array}$ & $\begin{array}{l}\text { lb } \\
\text { Shekelle } \\
\text { Jensen EA, } \\
2014\end{array}$ \\
\hline$\checkmark$ & $\begin{array}{l}\text { Es fundamental durante la evaluación } \\
\text { de seguimiento, interrogar y detallar los } \\
\text { factores pre y posnatales implicados } \\
\text { en el desarrollo de DBP, para definir } \\
\text { intervenciones oportunas }\end{array}$ & $\begin{array}{c}\text { Punto de buena } \\
\text { práctica }\end{array}$ \\
\hline
\end{tabular}


Laboratorio

\begin{tabular}{|c|l|c|}
\hline \multicolumn{2}{|c|}{ Evidencia/Recomendación } & Nivel/Grado \\
\hline $\mathrm{E}$ & $\begin{array}{l}\text { Se han propuesto una variedad de } \\
\text { biomarcadores detectados en fluidos } \\
\text { biológicos (sangre, orina, aspirado } \\
\text { traqueal), tanto en la madre como en } \\
\text { el recién nacido para la identificación } \\
\text { temprana de lactantes predispuestos a } \\
\text { DBP, sin embargo, hasta el momento no } \\
\text { son concluyentes }\end{array}$ & $\begin{array}{c}\text { Ilb } \\
\text { Shekelle }\end{array}$ \\
\hline$\checkmark$ & $\begin{array}{l}\text { No se recomienda realizar } \\
\text { biomarcadores con fines pronósticos }\end{array}$ & \\
\hline
\end{tabular}

Estudios de imagen

\begin{tabular}{|c|c|c|}
\hline \multicolumn{2}{|r|}{ Evidencia/Recomendación } & Nivel/Grado \\
\hline$E$ & $\begin{array}{l}\text { Las radiografías de tórax se utilizan } \\
\text { comúnmente para diagnosticar } \\
\text { complicaciones asociadas a DBP, pero } \\
\text { son poco sensibles, especialmente en lo } \\
\text { que respecta a la identificación cambios } \\
\text { estructurales. Los cambios radiológicos } \\
\text { que se pueden encontrar son enfisema, } \\
\text { densidades lineales y triangulares } \\
\text { subpleurales, aunque la mayoría } \\
\text { de los pacientes tienen pulmones } \\
\text { relativamente normales }\end{array}$ & $\begin{array}{l}\text { Ilb } \\
\text { Shekelle } \\
\text { Bhandari A, } \\
2013\end{array}$ \\
\hline$E$ & $\begin{array}{l}\text { Un pequeño timo en la radiografía de } \\
\text { tórax en el momento del nacimiento } \\
\text { puede predecir el desarrollo de DBP. } \\
\text { Un pequeño timo se define como: el } \\
\text { diámetro transversal de la imagen } \\
\text { cardiotimica a nivel de la carina/ } \\
\text { diámetro transversal del tórax < } 0.28 \text { en } \\
\text { la radiografía de tórax dentro de las seis } \\
\text { horas posteriores al nacimiento. Con } \\
\text { una sensibilidad } 94.1 \% \text {, especificidad } \\
98.3 \% \text {, valor predictivo positivo } 88.9 \% \text {, } \\
\text { valor predictivo negativo } 99.1 \%\end{array}$ & $\begin{array}{c}\text { la } \\
\text { Shekelle } \\
\text { DynaMed Plus, } \\
2017\end{array}$ \\
\hline$\checkmark$ & $\begin{array}{l}\text { La radiografía de tórax está indicada } \\
\text { como primer estudio radiológico en } \\
\text { todos los niños con DBP }\end{array}$ & $\begin{array}{c}\text { Punto de buena } \\
\text { práctica }\end{array}$ \\
\hline$E$ & $\begin{array}{l}\text { La tomografía de tórax es una } \\
\text { herramienta con alta sensibilidad para } \\
\text { obtener imágenes del parénquima } \\
\text { pulmonar y puede ser un predictor de } \\
\text { síntomas; aunque en ocasiones no } \\
\text { correlaciona con la función pulmonar }\end{array}$ & $\begin{array}{l}\text { III } \\
\text { Shekelle } \\
\text { van Mastrigt E, } \\
2016\end{array}$ \\
\hline$E$ & $\begin{array}{l}\text { Las características estructurales } \\
\text { anormales en la tomografía } \\
\text { computarizada de alta resolución } \\
\text { (TCAR) se han descrito en hasta } 85 \% \\
\text { de los pacientes con DBP. Las }\end{array}$ & $\begin{array}{l}\text { llb } \\
\text { Shekelle } \\
\text { Bhandari A, } \\
2013\end{array}$ \\
\hline
\end{tabular}

\begin{tabular}{|c|c|c|}
\hline & $\begin{array}{l}\text { anomalías radiológicas más comunes } \\
\text { son opacidades lineales y triangulares, } \\
\text { atrapamiento aéreo y mosaico de } \\
\text { perfusión; menos común se encuentra } \\
\text { consolidación y engrosamiento de la } \\
\text { pared bronquial } \\
\text { La extensión del enfisema en la TCAR } \\
\text { esta inversamente relacionado con su } \\
\text { FEV }\end{array}$ & \\
\hline$\checkmark$ & $\begin{array}{l}\text { La tomografía de tórax sólo está } \\
\text { indicada en niños con sospecha de } \\
\text { complicaciones o comorbilidades }\end{array}$ & $\begin{array}{l}\text { Punto de buena } \\
\text { práctica }\end{array}$ \\
\hline$E$ & $\begin{array}{l}\text { La resonancia magnética es } \\
\text { particularmente importante para niños } \\
\text { que son vulnerables a radiación } \\
\text { El gamagrama provee información } \\
\text { espacial de la distribución de la } \\
\text { perfusión y ventilación con tecnecio }\end{array}$ & $\begin{array}{c}\text { III } \\
\text { Shekelle } \\
\text { Walkup LL, } \\
2015\end{array}$ \\
\hline $\mathrm{R}$ & $\begin{array}{l}\text { Considerar resonancia magnética, } \\
\text { sólo en niños con DBP que tienen } \\
\text { complicaciones o comorbilidades y que } \\
\text { han sido sometidos a otros estudios con } \\
\text { altas dosis de radiación } \\
\text { El gamagrama no es de rutina. }\end{array}$ & $\begin{array}{c}\text { C } \\
\text { Shekelle } \\
\text { Walkup LL, } \\
2015\end{array}$ \\
\hline
\end{tabular}

Función respiratoria

\begin{tabular}{|c|c|c|}
\hline \multicolumn{2}{|r|}{ Evidencia/recomendación } & nivel/grado \\
\hline$E$ & $\begin{array}{l}\text { El efecto adverso del nacimiento muy } \\
\text { prematuro para la salud respiratoria } \\
\text { futura es evidente a pesar del progreso } \\
\text { en las prácticas de tratamiento durante } \\
\text { los primeros años de vida. La gravedad } \\
\text { de la DBP influye directamente sobre la } \\
\text { función pulmonar }\end{array}$ & $\begin{array}{l}\text { la Shekelle } \\
\text { Ronkainen E, } \\
\quad 2015\end{array}$ \\
\hline$E$ & $\begin{array}{l}\text { El grado de limitación del flujo de aire } \\
\text { en los primeros años de vida es un } \\
\text { buen predictor de la función pulmonar } \\
\text { futura }\end{array}$ & $\begin{array}{c}\text { la } \\
\text { Shekelle } \\
\text { El Mazloum } \\
\text { D, } 2014\end{array}$ \\
\hline$E$ & $\begin{array}{l}\text { Las alteraciones en la función pulmonar } \\
\text { son: menor capacidad vital forzada, } \\
\text { volumen espiratorio forzado en el primer } \\
\text { segundo }\left(\mathrm{VEF}_{1}\right) \text { y flujo espiratorio } \\
\text { forzado, así como un mayor volumen } \\
\text { residual }\end{array}$ & $\begin{array}{c}\text { la } \\
\text { Shekelle } \\
\text { McEvoy CT, } \\
2015\end{array}$ \\
\hline$E$ & $\begin{array}{l}\text { Estos valores son consistentemente } \\
\text { más bajos a cualquier edad. La } \\
\text { limitación del flujo aéreo durante la } \\
\text { infancia es el resultado de procesos de } \\
\text { remodelación temprana que afectan el } \\
\text { calibre de las vías respiratorias, del cual } \\
\text { los niños más gravemente afectados } \\
\text { nunca se recuperan por completo }\end{array}$ & $\begin{array}{c}\text { la } \\
\text { Shekelle } \\
\text { McEvoy CT, } \\
2015\end{array}$ \\
\hline
\end{tabular}




\begin{tabular}{|c|c|c|}
\hline $\mathrm{E}$ & $\begin{array}{l}\text { La obstrucción del flujo de aire no es } \\
\text { reversible en la mayoría de los niños } \\
\text { con DBP }\end{array}$ & $\begin{array}{l}\text { la } \\
\text { Shekelle } \\
\text { McEvoy CT, } \\
2015\end{array}$ \\
\hline$E$ & $\begin{array}{l}\text { Un } 50 \% \text { de los niños con DBP tienen } \\
\text { hiperreactividad de las vías respiratorias } \\
\text { a estímulos directos (histamina y } \\
\text { metacolina) y al ejercicio físico, incluso } \\
\text { si no tienen antecedentes clínicos de } \\
\text { sibilancias o enfermedad reactiva de las } \\
\text { vías respiratorias }\end{array}$ & $\begin{array}{l}\text { la } \\
\text { Shekelle } \\
\text { McEvoy CT, } \\
2015\end{array}$ \\
\hline$E$ & $\begin{array}{l}\text { En edad escolar, los niños con DBP } \\
\text { experimentan más tos crónica y } \\
\text { síntomas similares al asma que sus } \\
\text { pares y necesitan usar medicamentos } \\
\text { para el asma con más frecuencia que } \\
\text { los controles nacidos a término }\end{array}$ & $\begin{array}{c}\text { la } \\
\text { Shekelle } \\
\text { Carraro S, } \\
2013 \\
\text { Bhandari A, } \\
2013\end{array}$ \\
\hline $\mathrm{E}$ & $\begin{array}{l}\text { Tales síntomas se vuelven } \\
\text { gradualmente menos severos durante el } \\
\text { curso de la adolescencia }\end{array}$ & $\begin{array}{c}\text { la } \\
\text { Shekelle } \\
\text { Carraro S, } \\
2013 \\
\text { Bhandari A, } \\
2013\end{array}$ \\
\hline$E$ & $\begin{array}{l}\text { Los datos disponibles sobre la salud } \\
\text { respiratoria de los adultos son limitados, } \\
\text { pero aún sugieren que los adultos con } \\
\text { DBP que sobreviven tienden a tener } \\
\text { más síntomas respiratorios que sus } \\
\text { pares, así como hiperreactividad de las } \\
\text { vías respiratorias y menor tolerancia al } \\
\text { ejercicio }\end{array}$ & $\begin{array}{c}\text { la } \\
\text { Shekelle } \\
\text { Carraro S, } \\
2013 \\
\text { Bhandari A, } \\
2013\end{array}$ \\
\hline $\mathrm{E}$ & $\begin{array}{l}\text { En la cohorte EPIcure tras } 11 \text { años } \\
\text { de seguimiento de niños prematuros, } \\
\text { el } 56 \% \text { de los niños tuvo espirometría } \\
\text { anormal ( } 81 \% \text { niños con DBP) con VEF } \\
\text { disminuido. Yel } 27 \% \text { tuvieron respuesta } \\
\text { a broncodilatador }\end{array}$ & $\begin{array}{l}\text { la } \\
\text { Shekelle } \\
\text { McEvoy CT, } \\
2015\end{array}$ \\
\hline$E$ & $\begin{array}{l}\text { Los parámetros espirométricos no } \\
\text { parecen tener una recuperación } \\
\text { significativa a lo largo del tiempo. Los } \\
\text { adolescentes y adultos con DBP tienen } \\
\text { una función pulmonar persistentemente } \\
\text { reducida con limitación del flujo de } \\
\text { aire y con una tendencia hacia un } \\
\text { deterioro progresivo en la función } \\
\text { pulmonar, sobre todo en los que tienen } \\
\text { obstrucción del flujo aéreo severo } \\
\text { durante la infancia }\end{array}$ & $\begin{array}{c}\text { la } \\
\text { Shekelle } \\
\text { Carraro S, } \\
2013 \\
\text { Bhandari A, } \\
2013\end{array}$ \\
\hline $\mathrm{E}$ & $\begin{array}{l}\text { Se ha demostrado que, a pesar de } \\
\text { encontrarse sintomáticos, menos de la } \\
\text { mitad de los niños con obstrucción }\end{array}$ & $\begin{array}{c}\text { la } \\
\text { Shekelle }\end{array}$ \\
\hline
\end{tabular}

\begin{tabular}{|c|c|c|}
\hline & $\begin{array}{l}\text { de las vías respiratorias inferiores que } \\
\text { demostraron una respuesta positiva a } \\
\text { broncodilatador habían sido tratados } \\
\text { con broncodilatadores o esteroides } \\
\text { inhalados durante los últimos } 12 \text { meses }\end{array}$ & $\begin{array}{l}\text { Baker CD, } \\
2014\end{array}$ \\
\hline$E$ & $\begin{array}{l}\text { La respuesta broncodilatadora positiva } \\
\text { es más frecuente en los niños con DBP } \\
\text { moderada a grave }\end{array}$ & $\begin{array}{c}\text { la } \\
\text { Shekelle } \\
\text { Ronkainen E, } \\
2015\end{array}$ \\
\hline $\mathrm{R}$ & $\begin{array}{l}\text { Es necesario un control de la función } \\
\text { pulmonar de todos los niños con DBP } \\
\text { mediante un programa de seguimiento, } \\
\text { incluso si está asintomático; con énfasis } \\
\text { en los } 3 \text { primeros años posnatales }\end{array}$ & $\begin{array}{c}\text { A } \\
\text { Shekelle } \\
\text { Baker CD, } \\
2014\end{array}$ \\
\hline$E$ & $\begin{array}{l}\text { Los niños con DBP pueden tener } \\
\text { alteración en la capacidad de difusión } \\
\text { pulmonar de monóxido de carbono } \\
\text { (DLCO) }\end{array}$ & $\begin{array}{c}\text { la } \\
\text { Shekelle } \\
\text { Carraro S, } \\
2013 \\
\text { Bhandari A, } \\
2013\end{array}$ \\
\hline$E$ & $\begin{array}{l}\text { Los pacientes pediátricos con } \\
\text { DBP pueden tener una mayor } \\
\text { broncoconstricción inducida por el } \\
\text { ejercicio y un pico significativamente } \\
\text { menor en consumo de oxígeno, con } \\
\text { grados de reversibilidad variable }\end{array}$ & $\begin{array}{c}\text { la } \\
\text { Shekelle } \\
\text { Kotecha SJ, } \\
2015 \\
\text { Carraro S, } \\
2013 \\
\text { Bhandari A, } \\
2013\end{array}$ \\
\hline$E$ & $\begin{array}{l}\text { Pruebas de función pulmonar } \\
\text { La utilidad clínica de las pruebas de } \\
\text { función pulmonar en el menor de seis } \\
\text { años con DBP es: } \\
\text { - Control de la gravedad de la } \\
\text { enfermedad a lo largo del tiempo } \\
\text { - Evaluar la respuesta a los } \\
\text { tratamientos } \\
\text { - Medir objetivamente los estudios de } \\
\text { investigación clínica } \\
\text { Las pruebas de función pulmonar que } \\
\text { se pueden realizar en el menor de seis } \\
\text { años con DBP son dos: la técnica de } \\
\text { compresión toracoabdominal rápida } \\
\text { con volumen pulmonar aumentado } \\
\text { (CTARVA) y la babypletismografía. } \\
\text { Las cuales pueden ser herramientas } \\
\text { valiosas para abordar problemas } \\
\text { específicos, como los síntomas en } \\
\text { curso o monitorear la respuesta al } \\
\text { tratamiento. Sin embargo, hasta la fecha } \\
\text { no hay medidas estandarizadas para } \\
\text { poder realizar estas pruebas }\end{array}$ & $\begin{array}{c}\text { Ib } \\
\text { Shekelle } \\
\text { Rosenfeld M, } \\
2013\end{array}$ \\
\hline
\end{tabular}




\begin{tabular}{|l|l|l|}
\hline$\checkmark$ & $\begin{array}{l}\text { Hasta el momento no existen pruebas } \\
\text { suficientes para recomendar la } \\
\text { incorporación de las pruebas de función } \\
\text { pulmonar en la evaluación diagnóstica } \\
\text { de rutina y la monitorización clínica de } \\
\text { todos los lactantes y niños pequeños }\end{array}$ & \\
con DBP & \\
Sin embargo, el neumólogo pediatra & \\
puede requerir de acuerdo al estado & \\
clínico, edad y comorbilidades del & \\
paciente, alguna de las siguientes & \\
pruebas: gasometría arterial, & \\
babypletismografía, compresión & \\
toracoabdominal rápida con volumen & \\
pulmonar aumentado, oscilometría de & \\
impulso, espirometría, DLCO, prueba & \\
de esfuerzo con ejercicio, caminata de & \\
seis minutos & \\
\hline
\end{tabular}

Tratamiento

Líquidos

\begin{tabular}{|c|c|c|}
\hline \multicolumn{2}{|r|}{ Evidencia/Recomendación } & Nivel/Grado \\
\hline$E$ & $\begin{array}{l}\text { En los pacientes con DBP sin } \\
\text { comorbilidad, la ingesta recomendada } \\
\text { de líquidos se puede definir como } \\
150 \mathrm{~mL} / \mathrm{kg} / \text { día o más; por lo tanto, } \\
\text { consideramos una ingesta de líquidos } \\
\text { inferior a } 150 \mathrm{~mL} / \mathrm{kg} / \text { día como } \\
\text { 'restringida' } \\
\text { No hay una ventaja probada de } \\
\text { suministrar alimentos altamente } \\
\text { concentrados y de menor volumen. La } \\
\text { evidencia disponible es insuficiente para } \\
\text { apoyar o refutar el uso de restricción de } \\
\text { líquidos para los niños con DBP }\end{array}$ & $\begin{array}{c}\mathrm{lb} \\
\text { Shekelle } \\
\text { Barrington KJ, } \\
2017\end{array}$ \\
\hline $\mathrm{R}$ & $\begin{array}{l}\text { Es prudente restringir cuidadosamente } \\
\text { la ingesta de líquidos durante los } \\
\text { primeros días de vida mientras se } \\
\text { garantiza una adecuada nutrición } \\
\text { y evitando una deshidratación } \\
\text { significativa, asegurado un aporte } \\
\text { calórico-proteico, mientras se evita la } \\
\text { sobrecarga de líquidos para prevenir el } \\
\text { edema pulmonar }\end{array}$ & $\begin{array}{c}\text { A Shekelle Jain } \\
\text { D, } 2014\end{array}$ \\
\hline$\checkmark$ & $\begin{array}{l}\text { En el seguimiento a largo plazo del } \\
\text { paciente con DBP sin comorbilidad } \\
\text { (HP, cardiopatía, enfermedad renal), } \\
\text { es razonable mantener líquidos entre } \\
150-180 \mathrm{~mL} / \mathrm{kg} / \text { día garantizando un } \\
\text { adecuado aporte nutricional } \\
\text { Para determinar el aporte de líquidos } \\
\text { ideal en cada paciente se debe } \\
\text { asegurar que la cantidad de líquidos } \\
\text { administrada no genere datos clínicos } \\
\text { de edema agudo pulmonar (estertores, }\end{array}$ & $\begin{array}{c}\text { Punto de buena } \\
\text { práctica }\end{array}$ \\
\hline
\end{tabular}

\begin{tabular}{|l|l|l|}
\hline taquipnea, sibilancias, dificultad & \\
respiratoria, edema) \\
- La cantidad de líquidos cuantificada \\
debe incluir: leche, agua, papillas, \\
seno materno \\
- Se restringen líquidos, en caso \\
de edema agudo pulmonar, bajo \\
vigilancia hospitalaria & \\
- Se requiere individualizar el & \\
aporte de líquidos en pacientes & \\
con comorbilidades: cardiopatía, \\
nefropatía
\end{tabular}

Diuréticos

\begin{tabular}{|c|c|c|}
\hline \multicolumn{2}{|r|}{ Evidencia/Recomendación } & Nivel/Grado \\
\hline$E$ & $\begin{array}{l}\text { No hay evidencia que respalde que } \\
\text { el uso de diuréticos disminuya la } \\
\text { incidencia o el riesgo asociado de } \\
\text { mortalidad en los niños con DBP }\end{array}$ & $\begin{array}{l}\text { la } \\
\text { Shekelle } \\
\text { Johnson AK, } \\
2017\end{array}$ \\
\hline $\mathrm{R}$ & $\begin{array}{l}\text { No se recomienda el uso crónico de } \\
\text { diuréticos de asa en los niños con DBP }\end{array}$ & $\begin{array}{c}\text { A } \\
\text { Shekelle } \\
\text { Jain D, } \\
2014\end{array}$ \\
\hline$E$ & $\begin{array}{l}\text { La prescripción de los diuréticos debe } \\
\text { estar restringida a los cuadros agudos, } \\
\text { en los pacientes hipoxémicos con } \\
\text { signos de edema agudo pulmonar }\end{array}$ & $\begin{array}{l}\text { lb } \\
\text { Shekelle } \\
\text { Giubergia V, } \\
2013\end{array}$ \\
\hline $\mathrm{R}$ & $\begin{array}{l}\text { El diurético más utilizado en caso de } \\
\text { edema agudo pulmonar es furosemida } \\
\text { en dosis de } 1-2 \mathrm{mg} / \mathrm{kg} / \mathrm{día} \text {, por vía oral } \\
\text { o intravenosa, según el cuadro clínico } \\
\text { del paciente. Otra alternativa es la } \\
\text { hidroclorotiazida } 2-3 \mathrm{mg} / \mathrm{kg} / \text { día por vía } \\
\text { oral cada } 12 \text { horas }\end{array}$ & $\begin{array}{c}\text { A } \\
\text { Shekelle } \\
\text { Giubergia V, } \\
2013\end{array}$ \\
\hline
\end{tabular}

Broncodilatadores

\begin{tabular}{|c|c|c|}
\hline \multicolumn{2}{|r|}{ Evidencia/Recomendación } & Nivel/Grado \\
\hline$E$ & $\begin{array}{l}\text { Los pacientes con DBP tienen } \\
\text { aumento en la resistencia de las vías } \\
\text { respiratorias debido a hipertrofia del } \\
\text { músculo liso e hiperreactividad } \\
\text { No hay evidencia de que el uso de } \\
\text { broncodilatadores mejore el resultado } \\
\text { pulmonar a largo plazo }\end{array}$ & $\begin{array}{c}\text { la } \\
\text { Shekelle } \\
\text { Jain D, } 2014\end{array}$ \\
\hline $\mathrm{R}$ & $\begin{array}{l}\text { Actualmente el uso de } \\
\text { broncodilatadores de forma rutinaria no } \\
\text { está recomendado }\end{array}$ & $\begin{array}{c}\text { A } \\
\text { Shekelle } \\
\text { Jain D, } \\
2014\end{array}$ \\
\hline
\end{tabular}


Neumol Cir Torax. 2019; 78 (4): 371-394

\begin{tabular}{|c|c|c|}
\hline$E$ & $\begin{array}{l}\text { Entre el } 27-30 \% \text { de los niños con DBP } \\
\text { tienen respuesta a broncodilatador }\end{array}$ & $\begin{array}{c}\text { la } \\
\text { Shekelle } \\
\text { McEvoy CT, } \\
2015 \\
\text { Ronkainen E, } \\
2015\end{array}$ \\
\hline $\mathrm{R}$ & $\begin{array}{l}\text { En los niños con DBP y } \\
\text { broncoespasmo, la respuesta al } \\
\text { tratamiento broncodilatador es } \\
\text { heterogénea y debe usarse bajo } \\
\text { supervisión estrecha }\end{array}$ & $\begin{array}{l}\text { A } \\
\text { Shekelle } \\
\text { Clouse BJ, } \\
2016\end{array}$ \\
\hline $\mathrm{R}$ & $\begin{array}{l}\text { El uso de broncodilatadores debe } \\
\text { ser guiado por respuesta clínica y } \\
\text { reacciones adversas, limitando su uso } \\
\text { a pacientes con broncoespasmo y } \\
\text { respuesta clínica }\end{array}$ & $\begin{array}{c}\text { A } \\
\text { Shekelle } \\
\text { Ghanta S, } \\
2013\end{array}$ \\
\hline$\checkmark$ & $\begin{array}{l}\text { En los niños con DBP y } \\
\text { broncoespasmo puede administrarse } \\
\text { salbutamol en aerosol a través de } \\
\text { una aerocámara, o bien mediante } \\
\text { nebulizador (ambas medidas son igual } \\
\text { de efectivas), por un período no mayor } \\
\text { a siete días } \\
\text { En caso de una respuesta clínica } \\
\text { parcial con el uso de salbutamol, } \\
\text { está justificado realizar una prueba } \\
\text { con salbutamol en combinación con } \\
\text { bromuro de ipratropio y evaluar la } \\
\text { respuesta clínica. En caso de tener una } \\
\text { respuesta favorable (disminución de los } \\
\text { datos de broncoespasmo) continuar su } \\
\text { uso por un período no mayor a siete } \\
\text { días }\end{array}$ & $\begin{array}{l}\text { Punto de buena } \\
\text { práctica }\end{array}$ \\
\hline $\mathrm{E}$ & $\begin{array}{l}\text { No se han demostrado beneficios } \\
\text { con el uso crónico de salbutamol } \\
\text { o de broncodilatadores de acción } \\
\text { prolongada }\end{array}$ & $\begin{array}{l}\mathrm{lb} \\
\text { Shekelle } \\
\text { Giubergia V, } \\
2013\end{array}$ \\
\hline $\mathrm{R}$ & $\begin{array}{l}\text { No deberían indicarse en este grupo de } \\
\text { pacientes }\end{array}$ & $\begin{array}{c}\text { A } \\
\text { Shekelle } \\
\text { Giubergia V, } \\
2013\end{array}$ \\
\hline
\end{tabular}

Glucocorticoides inhalados

\begin{tabular}{|c|l|c|}
\hline \multicolumn{2}{|c|}{ Evidencia/Recomendación } & Nivel/Grado \\
\hline $\mathrm{E}$ & $\begin{array}{l}\text { En la mayoría de los estudios, los } \\
\text { lactantes con DBP que fueron tratados }\end{array}$ & $\mathrm{lb}$ \\
& Shekelle \\
& con terapia de glucocorticoides & \\
& inhalados, mostraron los siguientes & Clouse BJ, \\
& resultados sobre los tratados con & 2016 \\
& placebo: & \\
\hline
\end{tabular}

\begin{tabular}{|c|c|c|}
\hline & $\begin{array}{l}\text { - Reducción de la necesidad de } \\
\text { oxígeno suplementario } \\
\text { - Menos uso de esteroides sistémicos, } \\
\text { mejora en la distensibilidad pulmonar } \\
\text { - Disminución de resistencia de la vía } \\
\text { aérea } \\
\text { Sin embargo, algunos estudios } \\
\text { sugieren que los esteroides inhalados } \\
\text { no proporcionan ningún beneficio y } \\
\text { hasta el momento no se ha estudiado } \\
\text { una dosis estandarizada } \\
\text { Se necesita más investigación para } \\
\text { explorar las dosis seguras y efectivas } \\
\text { en la terapia con glucocorticoides } \\
\text { inhalados en lactantes con DBP }\end{array}$ & \\
\hline $\mathrm{R}$ & $\begin{array}{l}\text { En los pacientes con DBP que } \\
\text { presentan episodios de sibilancias } \\
\text { recurrentes no asociados a infecciones } \\
\text { virales, con antecedentes de asma } \\
\text { familiar, o ante la presencia de episodios } \\
\text { graves o reiterados, puede considerarse } \\
\text { la realización de una prueba terapéutica } \\
\text { con corticosteroides inhalados } \\
\text { Se sugiere iniciar un tratamiento en } \\
\text { dosis bajas (budesonida } 200 \text { } \mu \text { g/día o } \\
\text { equivalente) }{ }^{*} \text { y evaluar la respuesta } \\
\text { Si no se observa respuesta clínica } \\
\text { favorable luego de tres meses, se } \\
\text { recomienda suspender el tratamiento, } \\
\text { revisar el diagnóstico y descartar } \\
\text { comorbilidades }\end{array}$ & $\begin{array}{c}\text { A } \\
\text { Shekelle } \\
\text { Giubergia V, } \\
2013\end{array}$ \\
\hline
\end{tabular}

*Ver tabla de dosis equivalentes.

Oxígeno

Saturación percutánea de oxígeno $\left(\mathrm{SpO}_{2}\right)$ óptima

\begin{tabular}{|c|c|c|}
\hline \multicolumn{2}{|r|}{ Evidencia/Recomendación } & Nivel/Grado \\
\hline$E$ & $\begin{array}{l}\text { Los niños con DBP deben mantener un } \\
\text { nivel de } \mathrm{SpO}_{2} \geq 92 \% \text { con el objetivo de } \\
\text { evitar hipertensión pulmonar, favorecer } \\
\text { el crecimiento y mejorar la regulación } \\
\text { del sueño } \\
\text { Mantener valores de } \mathrm{SpO}_{2}>95 \% \\
\text { no produce beneficio alguno y debe } \\
\text { evitarse }\end{array}$ & $\begin{array}{c}\text { lb } \\
\text { Shekelle } \\
\text { Giubergia V, } \\
2013\end{array}$ \\
\hline$E$ & $\begin{array}{l}\text { La saturación de oxígeno objetivo } \\
\text { del } 85-89 \% \text { puede aumentar la } \\
\text { mortalidad antes del alta hospitalaria } \\
\text { en comparación con la saturación } \\
\text { de oxígeno de } 92 \%-95 \% \text { en recién } \\
\text { nacidos extremadamente prematuros }\end{array}$ & $\begin{array}{c}\text { la } \\
\text { Shekelle } \\
\text { DynaMed Plus, } \\
2017\end{array}$ \\
\hline $\mathrm{R}$ & $\begin{array}{l}\text { Los pacientes con DBP deben } \\
\text { mantener una } \mathrm{SpO}_{2} \text { entre } 92-95 \%\end{array}$ & $\begin{array}{c}\text { A } \\
\text { Shekelle } \\
\text { Giubergia V, } \\
2013\end{array}$ \\
\hline
\end{tabular}




\begin{tabular}{|c|c|c|}
\hline$E$ & $\begin{array}{l}\text { La evidencia actual indica que el } \\
\text { abordaje más seguro es la reanimación } \\
\text { neonatal con bajas concentraciones de } \\
\text { oxígeno (21-30\%).Y mantener un rango } \\
\text { de saturación de } 90-95 \% \text { posnatal }\end{array}$ & $\begin{array}{c}\text { la } \\
\text { Shekelle } \\
\text { Strueby L, } \\
2014\end{array}$ \\
\hline $\mathrm{R}$ & $\begin{array}{l}\text { Se recomienda una concentración } \\
\text { inicial de oxígeno del } 21-30 \% \text { para la } \\
\text { reanimación en la sala de partos y un } \\
\text { rango de saturación de oxígeno posnatal } \\
\text { del } 90-95 \% \text { en recién nacidos prematuros }\end{array}$ & $\begin{array}{l}\text { A } \\
\text { Shekelle } \\
\text { Strueby L, } \\
2014\end{array}$ \\
\hline$E$ & $\begin{array}{l}\text { No se han determinado los mejores } \\
\text { niveles de oxígeno para reducir la } \\
\text { retinopatía del prematuro (ROP), } \\
\text { reducir la morbilidad pulmonar y } \\
\text { aumentar la supervivencia y el } \\
\text { desarrollo cognitivo }\end{array}$ & $\begin{array}{c}\text { lb } \\
\text { Shekelle } \\
\text { Hartnett ME, } \\
2013\end{array}$ \\
\hline R & $\begin{array}{l}\text { Se recomienda en el manejo neonatal } \\
\text { (hasta } 40 \text { semanas de gestación } \\
\text { corregidas) mantener } \mathrm{SpO}_{2} \text { por arriba } \\
90 \%\end{array}$ & $\begin{array}{c}\text { A } \\
\text { Shekelle } \\
\text { Hartnett ME, } \\
2013\end{array}$ \\
\hline
\end{tabular}

Indicaciones para uso de oxígeno domiciliario en los pacientes con DBP

\begin{tabular}{|c|c|c|}
\hline \multicolumn{2}{|r|}{ Evidencia/Recomendación } & Nivel/Grado \\
\hline $\mathrm{E}$ & $\begin{array}{l}\text { La evaluación de los requerimientos de } \\
\text { oxígeno en el hogar para los pacientes } \\
\text { con DBP implica una combinación de } \\
\text { evaluación clínica, oximetría y análisis } \\
\text { intermitente de gases en sangre } \\
\text { El objetivo de la terapia con oxígeno } \\
\text { domiciliario es prevenir los efectos } \\
\text { de la hipoxemia crónica, que incluyen } \\
\text { la vasoconstricción pulmonar que } \\
\text { conduce a la hipertensión pulmonar, la } \\
\text { constricción bronquial que conduce a } \\
\text { la obstrucción de las vías respiratorias } \\
\text { y los cambios en el crecimiento de la } \\
\text { vasculatura pulmonar y ocular } \\
\text { La oxigenación adecuada puede dar } \\
\text { como resultado mejor crecimiento y } \\
\text { reparación pulmonar; mejora en la } \\
\text { nutrición y el crecimiento somático }\end{array}$ & $\begin{array}{c}\mathrm{lb} \\
\text { Shekelle } \\
\text { Fitzgerald DA, } \\
2008\end{array}$ \\
\hline$R$ & $\begin{array}{l}\text { Se indica oxígeno domiciliario a: } \\
\text { - Pacientes cuya } \mathrm{SpO}_{2} \text { respirando aire } \\
\text { ambiente sea }<92 \% \\
\text { - Pacientes cuya } \mathrm{SaO}_{2} \text { respirando aire } \\
\text { ambiente se encuentre entre } 92 \% \\
\text { y } 95 \% \text { y presenten alguna de las } \\
\text { siguientes situaciones: } \\
\text { - Signos de compromiso pulmonar } \\
\text { crónico y retraso del crecimiento } \\
\text { recibiendo el aporte nutricional } \\
\text { adecuado } \\
\text { - Diagnóstico de hipertensión } \\
\text { pulmonar }\end{array}$ & $\begin{array}{c}\text { A } \\
\text { Shekelle } \\
\text { Giubergia V, } \\
2013\end{array}$ \\
\hline
\end{tabular}

\begin{tabular}{|l|l|c|}
\hline$\checkmark$ & - Se debe evitar el uso de oxígeno & Punto de buena \\
& indirecto & práctica \\
& - En la mayoría de los casos debe \\
& administrarse el oxígeno a través de & \\
& puntas nasales & \\
& - En casos especiales (traqueostomía, \\
& malformación craneofaciall) es útil el \\
& uso de mascarilla & \\
\hline
\end{tabular}

Monitorización

\begin{tabular}{|c|c|c|}
\hline \multicolumn{2}{|r|}{ Evidencia/Recomendación } & Nivel/Grado \\
\hline$E$ & $\begin{array}{l}\text { La oximetría es el método de elección } \\
\text { para monitorización de la } \mathrm{SpO}_{2}\end{array}$ & $\begin{array}{c}\mathrm{lb} \\
\text { Shekelle } \\
\text { Giubergia V, } \\
2013\end{array}$ \\
\hline $\mathrm{R}$ & $\begin{array}{l}\text { Evaluar la presencia de hipoxemia } \\
\text { durante vigilia, alimentación, llanto y } \\
\text { períodos prolongados de sueño }\end{array}$ & $\begin{array}{c}\text { A } \\
\text { Shekelle } \\
\text { Giubergia V, } \\
2013\end{array}$ \\
\hline$E$ & $\begin{array}{l}\text { La oximetría intermitente no es } \\
\text { confiable y no debe usarse como } \\
\text { base para determinar la oxigenación } \\
\text { adecuada } \\
\text { La oximetría continua (seis horas } \\
\text { continuas) proporciona una mejor } \\
\text { información y es la de elección para la } \\
\text { monitorización de } \mathrm{SpO}_{2}\end{array}$ & $\begin{array}{c}\text { lb } \\
\text { Shekelle } \\
\text { Fitzgerald DA, } \\
2008\end{array}$ \\
\hline $\mathrm{R}$ & $\begin{array}{l}\text { Se requiere monitorizar con oximetría } \\
\text { continua (seis horas) con fines de } \\
\text { titular oxígeno tanto domiciliario como } \\
\text { hospitalario }\end{array}$ & $\begin{array}{c}\text { A } \\
\text { Shekelle } \\
\text { Fitzgerald DA, } \\
2008 \\
\end{array}$ \\
\hline$E$ & $\begin{array}{l}\text { Se puede determinar más información a } \\
\text { partir de la polisomnografía, que puede } \\
\text { proporcionar una medida fisiológica } \\
\text { objetiva del impacto de diferentes } \\
\text { niveles de oxígeno, el perfil de dióxido } \\
\text { de carbono y la calidad del sueño }\end{array}$ & $\begin{array}{c}\mathrm{lb} \\
\text { Shekelle } \\
\text { Fitzgerald DA, } \\
2008\end{array}$ \\
\hline$\checkmark$ & $\begin{array}{l}\text { Cuando esté disponible, deberá } \\
\text { realizarse polisomnografía en todos } \\
\text { los niños con DBP que utilizan oxígeno } \\
\text { domiciliario }\end{array}$ & $\begin{array}{l}\text { Punto de buena } \\
\text { práctica }\end{array}$ \\
\hline
\end{tabular}

Retiro de oxígeno domiciliario

\begin{tabular}{|c|l|c|}
\hline \multicolumn{2}{|l|}{ Evidencia/Recomendación } & Nivel/Grado \\
\hline $\mathrm{E}$ & $\begin{array}{l}\text { El retiro de oxígeno suplementario } \\
\text { usualmente ocurre antes de los dos }\end{array}$ & $\begin{array}{c}\text { Ilb } \\
\text { Shekelle }\end{array}$ \\
& $\begin{array}{l}\text { años de edad en la mayoría de los } \\
\text { niños con DBP, ya que la mayoría del } \\
\text { crecimiento alveolar posnatal ocurre } \\
\text { durante los primeros 2-3 años de vida }\end{array}$ & $\begin{array}{c}\text { Bhandari A, } \\
2013\end{array}$ \\
\hline
\end{tabular}




\begin{tabular}{|c|c|c|}
\hline$\checkmark$ & $\begin{array}{l}\text { Las condiciones que se deben } \\
\text { considerar en niño con DBP que aún } \\
\text { depende de oxígeno suplementario } \\
\text { después del segundo año de vida son: } \\
\text { traqueobroncomalacia, enfermedad por } \\
\text { reflujo gastroesofágico, síndrome de } \\
\text { aspiración recurrente, estenosis de la } \\
\text { vía aérea, granuloma en la vía aérea, } \\
\text { apnea del sueño, cardiopatía congénita, } \\
\text { hipertensión pulmonar, fibrosis quística, } \\
\text { enfermedad pulmonar intersticial }\end{array}$ & $\begin{array}{l}\text { Punto de buena } \\
\text { práctica }\end{array}$ \\
\hline$E$ & $\begin{array}{l}\text { Las herramientas utilizadas para el } \\
\text { retiro de oxígeno domiciliario incluyen } \\
\text { la evaluación clínica (frecuencia } \\
\text { respiratoria y crecimiento) combinada } \\
\text { con oximetría nocturna continua } \\
\text { o polisomnografía (cuando esté } \\
\text { disponible) y ecocardiograma }\end{array}$ & $\begin{array}{c}\text { lb } \\
\text { Shekelle } \\
\text { Giubergia V, } \\
2013\end{array}$ \\
\hline $\mathrm{R}$ & $\begin{array}{l}\text { La suspensión del oxígeno domiciliario } \\
\text { se inicia si el niño evoluciona con } \\
\text { crecimiento corporal normal y no } \\
\text { presenta signos de hipertensión } \\
\text { pulmonar (por ecocardiograma) durante } \\
\text { el último mes } \\
\text { 1. Se comienza durante los controles } \\
\text { clínicos ambulatorios, con pruebas } \\
\text { de } \mathrm{SpO}_{2} \text { en alimentación, llanto, } \\
\text { vigilili y aire ambiente } \\
\text { - Se considera fallido el intento si } \\
\text { la SpO promedio es < } 92 \% \text {, al } \\
\text { retirar el oxígeno suplementario } \\
\text { - Se considera exitoso: } \\
\text { - Si la SpO } 2 \text { } \geq 92 \% \text { con aire } \\
\text { ambiente } \\
\text { - Si después de 2-4 semanas } \\
\text { sin oxígeno domiciliario } \\
\quad \text { diurno, el aumento de peso es } \\
\text { satisfactorio y no ha habido } \\
\text { efectos adversos } \\
\text { 2. Se realiza un estudio de sueño } \\
\text { con aire ambiente, para determinar } \\
\text { que no haya desaturaciones. } \\
\text { Esta evaluación puede realizarse } \\
\text { mediante oximetría continua (seis } \\
\text { horas) o polisomnografía } \\
\text { Sin embargo, si la ganancia de peso } \\
\text { se detuvo manteniendo el mismo } \\
\text { aporte nutricional o hubo algún evento } \\
\text { adverso (desaturación, apnea, cianosis, } \\
\text { dificultad respiratoria) habrá que } \\
\text { reanudar el oxígeno } \\
\text { Durante los primeros tres meses de la } \\
\text { suspensión el paciente debe permanecer } \\
\text { con el equipo de oxígeno en su domicilio, } \\
\text { ya que si presentara comorbilidades } \\
\text { o complicaciones respiratorias podría } \\
\text { requerirlo nuevamente }\end{array}$ & $\begin{array}{c}\text { A } \\
\text { Shekelle } \\
\text { Giubergia V, } \\
2013\end{array}$ \\
\hline
\end{tabular}

\begin{tabular}{|l|l|c|}
\hline$\checkmark$ & $\begin{array}{l}\text { Al retirar el oxígeno se debe evaluar la } \\
\text { presencia de desaturación después de }\end{array}$ & $\begin{array}{c}\text { Punto de buena } \\
\text { práctica }\end{array}$ \\
& 40 minutos & \\
& $\begin{array}{l}\text { Se ha observado que las saturaciones } \\
\text { diurnas más bajas se alcanzan en ese } \\
\text { tiempo }\end{array}$ & \\
\hline
\end{tabular}

Condiciones durante los vuelos

\begin{tabular}{|c|c|c|}
\hline \multicolumn{2}{|r|}{ Evidencia/Recomendación } & Nivel/Grado \\
\hline$E$ & $\begin{array}{l}\text { El viaje en avión resulta en un } \\
\text { ambiente levemente hipóxico donde } \\
\text { la presión de la cabina equivalente a } \\
1,500-2,500 \text { metros sobre el nivel del } \\
\text { mar, da como resultado una fracción } \\
\text { equivalente de oxígeno inspirado }\left(\mathrm{FiO}_{2}\right) \\
\text { de aproximadamente } 15-17 \% \text { de la que } \\
\text { está a nivel del mar }\end{array}$ & $\begin{array}{c}\mathrm{lb} \\
\text { Shekelle } \\
\text { Fitzgerald DA, } \\
2008\end{array}$ \\
\hline $\mathrm{R}$ & $\begin{array}{l}\text { En caso de viaje en avión aumentar el } \\
\text { oxígeno en } 0.25 \text { litros por minuto a lo } \\
\text { previamente establecido } \\
\text { Si el paciente dejó de recibir terapia de } \\
\text { oxígeno suplementaria recién, se debe } \\
\text { administrar a } 0.25 \text { litros por minuto } \\
\text { durante el vuelo }\end{array}$ & $\begin{array}{c}\text { A } \\
\text { Shekelle } \\
\text { Fitzgerald DA, } \\
2008\end{array}$ \\
\hline
\end{tabular}

Otros tratamientos

\begin{tabular}{|c|c|c|}
\hline \multicolumn{2}{|r|}{ Evidencia/Recomendación } & Nivel/Grado \\
\hline $\mathrm{E}$ & $\begin{array}{l}\text { Los antagonistas del receptor } \\
\text { de leucotrienos (montelukast) se } \\
\text { encuentran en fases de investigación } \\
\text { (ensayos clínicos fase } 1 \text { y fase 2) }\end{array}$ & $\begin{array}{c}\text { la } \\
\text { Shekelle Ghanta } \\
\text { S, } 2013\end{array}$ \\
\hline$\checkmark$ & $\begin{array}{l}\text { Sólo se recomienda el uso de } \\
\text { montelukast, en la etapa perinatal, } \\
\text { en pacientes con DBP grave, estado } \\
\text { crítico y alto riesgo de muerte; con una } \\
\text { duración máxima de tres semanas } \\
\text { El uso de montelukast en el } \\
\text { seguimiento a largo plazo de DBP no } \\
\text { está justificado }\end{array}$ & $\begin{array}{l}\text { Punto de buena } \\
\text { práctica }\end{array}$ \\
\hline$E$ & $\begin{array}{l}\text { La administración de vitamina } A \text { es una } \\
\text { estrategia para disminuir la incidencia } \\
\text { de DBP } \\
\text { La vitamina A disminuye } \\
\text { rehospitalizaciones, uso de oxígeno } \\
\text { domiciliario, uso de broncodilatadores } \\
\text { y diuréticos, e indirectamente mejora el } \\
\text { desarrollo neurológico } \\
\text { Si hay comorbilidad no funciona la } \\
\text { vitamina A } \\
\text { Pocos estudios encontraron efectos } \\
\text { adversos }\end{array}$ & $\begin{array}{c}\text { Ila } \\
\text { Shekelle } \\
\text { Gawronski CA, } \\
2016\end{array}$ \\
\hline $\mathrm{R}$ & $\begin{array}{l}\text { En recién nacidos prematuros de muy } \\
\text { bajo peso al nacer de } 26 \text { a } 30\end{array}$ & $\begin{array}{c}\text { B } \\
\text { Shekelle }\end{array}$ \\
\hline
\end{tabular}




\begin{tabular}{|c|c|c|}
\hline & $\begin{array}{l}\text { semanas, se utiliza vitamina A. Existen } \\
\text { dos esquemas de aplicación: } \\
\text { - Vitamina A dosis } 2,000 \text { UI, } 14 \\
\text { inyecciones intramusculares durante } \\
28 \text { días (aplicadas un día sí y un día } \\
\text { no), a partir del cuarto día de vida } \\
\text { extrauterina } \\
\text { - Vitamina A 5,000 UI inyección } \\
\text { intramuscular tres veces por semana } \\
\text { (por ejemplo, lunes, miércoles y } \\
\text { viernes) en total } 12 \text { dosis (duración } \\
\text { cuatro semanas). A partir de cuarto } \\
\text { día de vida extrauterina }\end{array}$ & $\begin{array}{c}\text { Gawronski CA, } \\
2016\end{array}$ \\
\hline$E$ & $\begin{array}{l}\text { La administración de MSC derivadas } \\
\text { de médula ósea por vía intratraqueal, } \\
\text { intravenosa o intraperitoneal se } \\
\text { encuentra en estudio con la finalidad } \\
\text { de atenuar la inflamación pulmonar, la } \\
\text { detención del crecimiento alveolar y el } \\
\text { daño vascular pulmonar }\end{array}$ & $\begin{array}{c}\text { la } \\
\text { Shekelle } \\
\text { Strueby L, } \\
2014\end{array}$ \\
\hline
\end{tabular}

Comorbilidades y complicaciones Hipertensión pulmonar (HP)

\begin{tabular}{|c|c|c|}
\hline \multicolumn{2}{|r|}{ Evidencia/Recomendación } & Nivel/Grado \\
\hline$E$ & $\begin{array}{l}\text { El aumento de la resistencia vascular } \\
\text { pulmonar conduce a la elevación de la } \\
\text { presión arterial pulmonar en algunos } \\
\text { pacientes con DBP, hipertrofia del VD y } \\
\text { ocasionalmente insuficiencia cardíaca } \\
\text { La asociación de hipertensión pulmonar } \\
\text { y displasia broncopulmonar (HP. } \\
\text { DBP) están influenciados por factores } \\
\text { genéticos, epigenéticos y ambientales } \\
\text { Los factores de riesgo reconocidos } \\
\text { para la HP en la población con } \\
\text { DBP son: prematurez extrema, } \\
\text { restricción del crecimiento } \\
\text { intrauterino, oligohidramnios, } \\
\text { duración prolongada de la ventilación } \\
\text { mecánica, preeclampsia. La } \\
\text { enterocolitis necrosante, la hemorragia } \\
\text { intraventricular grave y el peso bajo al } \\
\text { nacer se asocian independientemente } \\
\text { con HP }\end{array}$ & $\begin{array}{c}\text { lb } \\
\text { Shekelle } \\
\text { Altit G, } \\
2017\end{array}$ \\
\hline$E$ & $\begin{array}{l}\text { La DBP es la causa respiratoria más } \\
\text { común de HP }\end{array}$ & $\begin{array}{c}\text { lb } \\
\text { Shekelle } \\
\text { Wardle AJ, } \\
2013\end{array}$ \\
\hline$E$ & $\begin{array}{l}\text { La HP concomitante tiene una } \\
\text { prevalencia en el rango de } 17 \text { a } 43 \% \text {. } \\
\text { Se asocia con una mayor tasa de } \\
\text { mortalidad en lactantes con DBP }\end{array}$ & $\begin{array}{l}\text { la } \\
\text { Shekelle } \\
\text { Carraro S, } \\
2013\end{array}$ \\
\hline
\end{tabular}

\begin{tabular}{|c|c|c|}
\hline$E$ & $\begin{array}{l}\text { Las tasas de supervivencia de } \\
\text { HP asociada a DBP después del } \\
\text { diagnóstico, es de } 64 \% \text { a los seis } \\
\text { meses; } 61 \% \text { y } 52 \% \text { a uno y dos años, } \\
\text { respectivamente } \\
\text { La gravedad de la HP es un factor } \\
\text { pronóstico de DBP, aumentando la } \\
\text { mortalidad hasta cuatro veces }\end{array}$ & $\begin{array}{c}\mathrm{lb} \\
\text { Shekelle } \\
\text { Wardle AJ, } \\
2013\end{array}$ \\
\hline$E$ & $\begin{array}{l}\text { La ecocardiografía es actualmente } \\
\text { la modalidad más ampliamente } \\
\text { utilizada para estimar las presiones } \\
\text { pulmonares y la función del VD en los } \\
\text { primeros años de vida. Es accesible, } \\
\text { no invasivo y portátil. El diagnóstico } \\
\text { ecocardiográfico de la HP es correcto } \\
\text { en el } 79 \% \text { de la población, pero su } \\
\text { precisión para la severidad es de sólo } \\
47 \% \\
\text { El cateterismo cardíaco no es un } \\
\text { examen factible para toda la población }\end{array}$ & $\begin{array}{c}\text { lb } \\
\text { Shekelle } \\
\text { Altit G, } \\
2017\end{array}$ \\
\hline$E$ & $\begin{array}{l}\text { El estándar de oro para el diagnóstico } \\
\text { de HP se define como presión arterial } \\
\text { pulmonar media } \geq 25 \mathrm{mmHg} \text { en reposo } \\
\text { mediante cateterismo cardíaco. Sin } \\
\text { embargo, esto es invasivo y, por lo } \\
\text { tanto, el uso de cribado mediante } \\
\text { ecocardiografía Doppler con una } \\
\text { velocidad de regurgitación tricuspídea } \\
\text { (RT) mayor a } 2.8 \mathrm{~m} / \mathrm{s} \text {, que corresponde } \\
\text { a una presión sistólica de la arteria } \\
\text { pulmonar (PSAP) de aproximadamente } \\
36 \mathrm{mmHg} \text {, es aceptada }\end{array}$ & $\begin{array}{c}\mathrm{lb} \\
\text { Shekelle } \\
\text { Wardle AJ, } \\
2013\end{array}$ \\
\hline$R$ & $\begin{array}{l}\text { Se debe realizar cribado para detección } \\
\text { de HP, mediante ecocardiograma, en } \\
\text { todos los niños con DBP }\end{array}$ & $\begin{array}{c}\text { A } \\
\text { Shekelle } \\
\text { Altit G, } \\
2017\end{array}$ \\
\hline$R$ & $\begin{array}{l}\text { Se recomienda cateterismo en aquellos } \\
\text { pacientes con: } \\
\text { - DBP que presentan signos } \\
\text { persistentes de enfermedad } \\
\text { cardiorrespiratoria grave o deterioro } \\
\text { del estado clínico no relacionado con } \\
\text { patología respiratoria } \\
\text { - En aquellos con sospecha de HP } \\
\text { significativa a pesar del tratamiento } \\
\text { de la enfermedad pulmonar } \\
\text { - En los pacientes que se considera } \\
\text { tratamiento farmacológico para HP } \\
\text { a largo plazo antes del inicio de la } \\
\text { terapia } \\
\text { - Y en aquellos con edema pulmonar } \\
\text { recurrente inexplicado }\end{array}$ & $\begin{array}{c}\text { A } \\
\text { Shekelle } \\
\text { Altit G, } \\
2017\end{array}$ \\
\hline$E$ & $\begin{array}{l}\text { En la mayoría de los pacientes, la HP- } \\
\text { DBP se resuelve gradualmente en el } \\
\text { transcurso del primer año de vida; }\end{array}$ & $\begin{array}{c}\mathrm{lb} \\
\text { Shekelle }\end{array}$ \\
\hline
\end{tabular}


Neumol Cir Torax. 2019; 78 (4): 371-394

\begin{tabular}{|c|c|c|}
\hline & $\begin{array}{l}\text { sin embargo, el tratamiento activo es } \\
\text { obligatorio para evitar la insuficiencia } \\
\text { cardíaca derecha fatal (cor pulmonale) } \\
\text { El oxígeno es el vasodilatador más } \\
\text { potente y el pilar de la terapia, pero con } \\
\text { tratamiento único de oxígeno la HP- } \\
\text { DBP tiene una mortalidad de hasta el } \\
50 \% \text { y la mayoría de estas muertes se } \\
\text { relacionan directamente con la HP } \\
\text { La monoterapia con sildenafil muestra } \\
\text { un } 81 \% \text { de supervivencia a los } 12 \\
\text { meses ya que mejora la función } \\
\text { ventricular derecha de forma duradera }\end{array}$ & $\begin{array}{l}\text { Wardle AJ, } \\
2013\end{array}$ \\
\hline $\mathrm{R}$ & $\begin{array}{l}\text { Se debe atacar de forma agresiva } \\
\text { los factores que contribuyen a la } \\
\text { enfermedad pulmonar como episodios } \\
\text { de hipoxia, insuficiencia ventilatoria, } \\
\text { broncoconstricción, reflujo y aspiración } \\
\text { crónicos; infecciones respiratorias, } \\
\text { así como obstrucción de la vía aérea } \\
\text { superior e inferior }\end{array}$ & $\begin{array}{c}\text { A } \\
\text { Shekelle } \\
\text { Mourani PM, } \\
2013\end{array}$ \\
\hline $\mathrm{R}$ & $\begin{array}{l}\text { Se recomienda mantener una } \mathrm{SpO}_{2} \text { de } \\
92-95 \% \text {, para evitar } \mathrm{HP} \text { en los niños } \\
\text { con DBP }\end{array}$ & $\begin{array}{c}\text { A } \\
\text { Shekelle } \\
\text { Berkelhamer SK, } \\
2013\end{array}$ \\
\hline $\mathrm{R}$ & $\begin{array}{l}\text { El sildenafil se utiliza para tratamiento } \\
\text { de HP-DBP en dosis } 1-3 \mathrm{mg} / \mathrm{kg} / \mathrm{día} \\
\text { divididos cada 6-8 } \mathrm{h} \text { vía oral } \\
\text { Los niños en tratamiento deben ser } \\
\text { evaluados de forma ambulatoria en } \\
\text { cardiología pediátrica cada dos meses } \\
\text { El tratamiento debe reducirse } \\
\text { gradualmente y detenerse cuando el } \\
\text { paciente esta asintomático y tiene dos } \\
\text { ecocardiogramas seriados negativos } \\
\text { para HP }\end{array}$ & $\begin{array}{c}\text { A } \\
\text { Shekelle } \\
\text { Wardle AJ, } \\
2013\end{array}$ \\
\hline$E$ & $\begin{array}{l}\text { De acuerdo con el estudio STARTS-1 } \\
\text { las dosis altas de sildenafil en } \\
\text { comparación con las dosis bajas, } \\
\text { incrementa el riesgo de mortalidad } \\
\text { En la evaluación riesgo-beneficio, los } \\
\text { datos se muestran favorables para el } \\
\text { uso de sildenafil en dosis bajas }\end{array}$ & $\begin{array}{c}\text { la } \\
\text { Shekelle } \\
\text { Jobe AH, } \\
2014\end{array}$ \\
\hline $\mathrm{R}$ & $\begin{array}{l}\text { Se debe utilizar dosis bajas de sildenafil } \\
\text { y no suspender abruptamente el } \\
\text { tratamiento }\end{array}$ & $\begin{array}{c}\text { A } \\
\text { Shekelle } \\
\text { Jobe AH, } \\
2014\end{array}$ \\
\hline$E$ & $\begin{array}{l}\text { Óxido nítrico } \\
\text { El tratamiento crónico con óxido nítrico } \\
\text { inhalado todavía no es práctico en } \\
\text { el ámbito ambulatorio, debido a la } \\
\text { logística del tratamiento continuo con } \\
\text { un medicamento inhalado }\end{array}$ & $\begin{array}{c}\mathrm{lb} \\
\text { Shekelle } \\
\text { Berkelhamer SK, } \\
2013\end{array}$ \\
\hline
\end{tabular}

\begin{tabular}{|c|c|c|}
\hline$E$ & $\begin{array}{l}\text { Prostaciclina } \\
\text { La eficacia y la seguridad de esta } \\
\text { terapia todavía se están explorando } \\
\text { actualmente en la HP asociado con } \\
\text { DBP }\end{array}$ & $\begin{array}{l}\text { lb } \\
\text { Shekelle } \\
\text { Berkelhamer SK, } \\
2013\end{array}$ \\
\hline$E$ & $\begin{array}{l}\text { Bosentán } \\
\text { Existe una experiencia limitada con el } \\
\text { uso de bosentán para el tratamiento de } \\
\text { la HP en lactantes con DBP }\end{array}$ & $\begin{array}{l}\text { lb } \\
\text { Shekelle } \\
\text { Berkelhamer SK, } \\
2013\end{array}$ \\
\hline$E$ & $\begin{array}{l}\text { Los niños con DBP-HP tienen un } \\
\text { mayor riesgo de crisis de HP mientras } \\
\text { están bajo anestesia o sedación y } \\
\text { esto contribuye a su mayor mortalidad, } \\
\text { tienen un riesgo seis veces mayor de } \\
\text { riesgo cardíaco perioperatorio }\end{array}$ & $\begin{array}{c}\mathrm{lb} \\
\text { Shekelle } \\
\text { Rossor T, } 2015\end{array}$ \\
\hline $\mathrm{R}$ & $\begin{array}{l}\text { En aquellos pacientes de alto riesgo } \\
\text { sin respuesta al tratamiento habrá que } \\
\text { considerar septostomía auricular o } \\
\text { trasplante pulmonar }\end{array}$ & $\begin{array}{l}\text { A } \\
\text { Shekelle } \\
\text { Nicolarsen J, } \\
2014\end{array}$ \\
\hline
\end{tabular}

Exacerbación de la displasia broncopulmonar

\begin{tabular}{|c|c|c|}
\hline \multicolumn{2}{|r|}{ Evidencia/Recomendación } & Nivel/Grado \\
\hline$E$ & $\begin{array}{l}\text { Durante los primeros dos años de vida, } \\
\text { el principal problema está representado } \\
\text { por exacerbaciones respiratorias, } \\
\text { causadas principalmente por } \\
\text { infecciones virales. Durante esta etapa } \\
\text { hasta } 50 \% \text { de los pacientes con DBP } \\
\text { serán rehospitalizados por enfermedad } \\
\text { respiratoria } \\
\text { Los pacientes con DBP que necesitan } \\
\text { oxígeno suplementario domiciliario, } \\
\text { tienen un curso particularmente grave, } \\
\text { con hospitalizaciones más frecuentes }\end{array}$ & $\begin{array}{c}\text { la } \\
\text { Shekelle } \\
\text { Carraro S, } \\
2013 \\
\text { Strueby L, } \\
2014\end{array}$ \\
\hline$E$ & $\begin{array}{l}\text { La infección respiratoria más frecuente } \\
\text { en los niños con DBP durante } \\
\text { los primeros meses de vida es la } \\
\text { bronquiolitis. El agente causal más } \\
\text { frecuente es el VSR } \\
\text { Los lactantes con DB e infección por } \\
\text { VSR, pueden requerir nuevamente } \\
\text { oxígeno domiciliario } \\
\text { La DBP es un factor de riesgo } \\
\text { establecido para la aparición de } \\
\text { bronquiolitis grave y mayor riesgo de } \\
\text { hospitalización }\end{array}$ & $\begin{array}{c}\mathrm{lb} \\
\text { Shekelle } \\
\text { Giubergia V, } \\
2013 \\
\text { Carraro S, } \\
2013\end{array}$ \\
\hline$\checkmark$ & $\begin{array}{l}\text { Se recomienda la administración de } \\
\text { palivizumab para todos los niños } \\
\text { menores de un año con DBP } \\
\text { Y para los menores de dos años con } \\
\text { DBP que hayan requerido tratamiento } \\
\text { (oxígeno suplementario, }\end{array}$ & $\begin{array}{c}\text { Punto de buena } \\
\text { práctica }\end{array}$ \\
\hline
\end{tabular}


Neumol Cir Torax. 2019; 78 (4): 371-394

\begin{tabular}{|l|l|l|}
\hline broncodilatadores, diuréticos, esteroide & \\
inhalado) en los seis meses anteriores & \\
al inicio de la estación de VSR & \\
(noviembre - marzo) & \\
La dosis de palivizumab es $15 \mathrm{mg} / \mathrm{kg}$ & \\
de peso por vía intramuscular, mensual, & \\
por un máximo de cinco dosis & \\
\hline
\end{tabular}

Asma, sibilancias recurrentes y displasia broncopulmonar

\begin{tabular}{|c|c|c|}
\hline \multicolumn{2}{|r|}{ Evidencia/Recomendación } & Nivel/Grado \\
\hline$E$ & $\begin{array}{l}\text { Los niños que nacieron } \\
\text { prematuramente presentan mayor } \\
\text { prevalencia de sibilancias recurrentes } \\
\text { no asociadas a infecciones } \\
\text { respiratorias } \\
\text { Es frecuente que se clasifique } \\
\text { erróneamente como asmáticos a los } \\
\text { niños con antecedentes de DBP con } \\
\text { sibilancias recurrentes y espirometría con } \\
\text { evidencia de obstrucción al flujo aéreo }\end{array}$ & $\begin{array}{l}\text { lb } \\
\text { Shekelle } \\
\text { Giubergia V. } \\
2013\end{array}$ \\
\hline$E$ & $\begin{array}{l}\text { Hasta } 25 \% \text { de los niños con DBP } \\
\text { son catalogados como asmáticos, } \\
\text { pero los niños con DBP tienen menos } \\
\text { probabilidades de tener reversibilidad } \\
\text { al agonista beta } 2 \text { y tienen niveles } \\
\text { significativamente más bajos de óxido } \\
\text { nítrico exhalado y una peor respuesta } \\
\text { a los corticosteroides inhalados en } \\
\text { comparación a los niños con asma }\end{array}$ & $\begin{array}{l}\text { llb } \\
\text { Shekelle } \\
\text { Bhandari A, } \\
2013\end{array}$ \\
\hline$E$ & $\begin{array}{l}\text { El asma y la DBP son dos diferentes } \\
\text { enfermedades obstructivas del pulmón, } \\
\text { que no comparten el mismo tipo de } \\
\text { inflamación de la vía aérea }\end{array}$ & $\begin{array}{l}\text { la } \\
\text { Shekelle } \\
\text { El Mazloum D, } \\
2014\end{array}$ \\
\hline$\checkmark$ & $\begin{array}{l}\text { En niños con DBP y sibilancias } \\
\text { recurrentes se requiere un seguimiento } \\
\text { estrecho a largo plazo. Y requieren } \\
\text { evaluación por el neumólogo pediatra } \\
\text { para tratamiento dirigido y pruebas de } \\
\text { función pulmonar } \\
\text { El neumólogo pediatra a través del } \\
\text { historial clínico, el estado y evolución } \\
\text { clínica de cada paciente, las pruebas } \\
\text { de función pulmonar, el estudio } \\
\text { y tratamiento de comorbilidades, } \\
\text { evaluará la necesidad del uso de } \\
\text { fármacos agonistas beta } 2 \text { de acción } \\
\text { corta, acción larga y corticosteroides } \\
\text { inhalados } \\
\text { Tomando en consideración: } \\
\text { - La respuesta clínica y las pruebas } \\
\text { de función pulmonar de cada } \\
\text { paciente } \\
\text { - La seguridad del fármaco efectos adversos }\end{array}$ & $\begin{array}{c}\text { Punto de buena } \\
\text { práctica }\end{array}$ \\
\hline
\end{tabular}

Enfermedad de vía aérea y otros problemas respiratorios asociados

\begin{tabular}{|c|c|c|}
\hline \multicolumn{2}{|r|}{ Evidencia/Recomendación } & Nivel/Grado \\
\hline$E$ & $\begin{array}{l}\text { Los lactantes con DBP pueden tener } \\
\text { falla al retiro de la ventilación mecánica } \\
\text { y más ingresos hospitalarios debido } \\
\text { a problemas de la vía aérea superior, } \\
\text { como resultado de una intubación } \\
\text { prolongada o reiterada }\end{array}$ & $\begin{array}{l}\text { la } \\
\text { Shekelle } \\
\text { Carraro S, } \\
2013\end{array}$ \\
\hline$E$ & $\begin{array}{l}\text { Las complicaciones inmediatas de la } \\
\text { ventilación invasiva son: } \\
\text { - Abrasión y laceración orofaríngea, } \\
\text { hipofaríngea y laríngea; la fijación } \\
\text { cricoaritenoidea, formación de } \\
\text { granulomas y estenosis subglótica } \\
\text { son relativamente frecuentes } \\
\text { - La dislocación cricoaritenoidea, } \\
\text { perforación esofágica, ruptura } \\
\text { traqueal y absceso retrofaríngeo } \\
\text { están reportados } \\
\text { - Deformación de vía } \\
\text { aérea y alteración de la } \\
\text { complianza, traqueomegalia y } \\
\text { traqueobroncomalacia }\end{array}$ & $\begin{array}{l}\text { III } \\
\text { Shekelle } \\
\text { Zhang H, } \\
2016\end{array}$ \\
\hline $\mathrm{R}$ & $\begin{array}{l}\text { En niños que se extuban, pero presentan } \\
\text { distrés respiratorio y/o falla al retiro de la } \\
\text { ventilación mecánica, se deben evaluar } \\
\text { despiertos mediante laringoscopia } \\
\text { transnasal para evaluar estructuras } \\
\text { supraglóticas (quistes-laringomalacia) y } \\
\text { la función glótica (parálisis de cuerdas } \\
\text { vocales, granulomas, edema) } \\
\text { Previo a decanular se recomienda } \\
\text { realizar broncoscopia para confirmar la } \\
\text { idoneidad anatómica } \\
\text { En caso de encontrar diagnósticos } \\
\text { corregibles, se requerirá intervención } \\
\text { antes de intentar extubación } \\
\text { (granulomas, quistes subglóticos, } \\
\text { compresiones vasculares) }\end{array}$ & $\begin{array}{l}\text { A } \\
\text { Shekelle } \\
\text { Amin RS, } \\
2015\end{array}$ \\
\hline$E$ & $\begin{array}{l}\text { De los lactantes con DBP nacidos } \\
\text { antes de las } 30 \text { semanas de gestación, } \\
\text { el } 3 \text { al } 7 \% \text { requieren traqueostomía }\end{array}$ & $\begin{array}{l}\mathrm{lb} \\
\text { Shekelle } \\
\text { Amin RS, } \\
2015\end{array}$ \\
\hline $\mathrm{R}$ & $\begin{array}{l}\text { En niños con falla al retiro del ventilador, } \\
\text { laringitis extrema, falla de tratamiento } \\
\text { endoscópico o quirúrgico y en quienes } \\
\text { es improbable extubarlos a corto plazo, } \\
\text { la traqueostomía es una opción }\end{array}$ & $\begin{array}{l}\text { A } \\
\text { Shekelle } \\
\text { Amin RS, } \\
2015\end{array}$ \\
\hline
\end{tabular}

Trastornos del sueño

\begin{tabular}{|l|l|c|}
\hline \multicolumn{2}{|c|}{ Evidencia/Recomendación } & Nivel/Grado \\
\hline $\mathrm{E}$ & $\begin{array}{l}\text { La prematurez es factor de riesgo } \\
\text { para trastornos respiratorios del sueño } \\
\text { durante la infancia }\end{array}$ & $\begin{array}{c}\mathrm{lb} \\
\text { Shekelle }\end{array}$ \\
\hline
\end{tabular}




\begin{tabular}{|l|l|c|}
\hline & $\begin{array}{l}\text { Los lactantes con DBP tienen mayor } \\
\text { riesgo de muerte súbita y apnea } \\
\text { obstructiva durante el sueño que los } \\
\text { niños de la misma edad sin DBP, esto } \\
\text { debido a falta de mecanismos de } \\
\text { defensa como autoresucitación } \\
\text { Las apneas ocurren con mayor } \\
\text { frecuencia en decúbito prono que en } \\
\text { decúbito supino }\end{array}$ & $\begin{array}{c}\text { Bates ML, } \\
2013\end{array}$ \\
\hline $\mathrm{R}$ & $\begin{array}{l}\text { Todos los niños deben dormir en } \\
\text { decúbito supino, para evitar muerte } \\
\text { súbita del lactante }\end{array}$ & $\begin{array}{c}\text { Shekelle } \\
\text { Bates ML, } \\
2013\end{array}$ \\
\hline$\checkmark$ & $\begin{array}{l}\text { En caso de contar con el recurso, } \\
\text { realizar polisomnografía en lactantes } \\
\text { con DBP moderada y grave }\end{array}$ & $\begin{array}{c}\text { Punto de buena } \\
\text { práctica }\end{array}$ \\
\hline
\end{tabular}

Enfermedad pulmonar obstructiva crónica (EPOC)

\begin{tabular}{|c|c|c|}
\hline & Evidencia/Recomendación & Nivel/Grado \\
\hline$E$ & $\begin{array}{l}\text { Las anormalidades persistentes en } \\
\text { las vías respiratorias presentan la } \\
\text { posibilidad de que los sobrevivientes } \\
\text { puedan estar en riesgo de desarrollar } \\
\text { un fenotipo de enfermedad pulmonar } \\
\text { obstructiva crónica (EPOC) con sus } \\
\text { complicaciones concomitantes a } \\
\text { medida que envejecen }\end{array}$ & $\begin{array}{l}\text { Ilb } \\
\text { Shekelle } \\
\text { Bhandari A, } \\
2013\end{array}$ \\
\hline$E$ & $\begin{array}{l}\text { Los adultos sobrevivientes de DBP } \\
\text { tienen menos síntomas respiratorios } \\
\text { que los niños, pero la limitación del } \\
\text { flujo de aire persiste. Algunos de ellos } \\
\text { nunca alcanzan la función pulmonar } \\
\text { máxima esperada al principio de la } \\
\text { edad adulta y pueden experimentar un } \\
\text { ritmo acelerado de disminución de la } \\
\text { función pulmonar que los predispone a } \\
\text { la morbilidad respiratoria a lo largo de } \\
\text { sus vidas } \\
\text { Las secuelas respiratorias a largo } \\
\text { plazo de la DBP pueden no ser } \\
\text { familiares para los neumólogos de } \\
\text { adultos y, en consecuencia, pueden } \\
\text { ser subestimados o ignorados }\end{array}$ & $\begin{array}{l}\text { la } \\
\text { Shekelle } \\
\text { El Mazloum D, } \\
2014\end{array}$ \\
\hline $\mathrm{R}$ & $\begin{array}{l}\text { El neumólogo de adultos debe llevar el } \\
\text { seguimiento de los pacientes con DBP } \\
\text { y tomar las medidas pertinentes para } \\
\text { evitar comorbilidades y complicaciones }\end{array}$ & $\begin{array}{c}\text { A } \\
\text { Shekelle } \\
\text { El Mazloum D, } \\
2014\end{array}$ \\
\hline$\checkmark$ & $\begin{array}{l}\text { Los pacientes con DBP requieren } \\
\text { seguimiento durante toda su vida, por lo } \\
\text { que el médico pediatra y/o neumólogo } \\
\text { pediatra deben procurar el seguimiento } \\
\text { con neumología de adultos }\end{array}$ & $\begin{array}{c}\text { Punto de buena } \\
\text { práctica }\end{array}$ \\
\hline
\end{tabular}

Nutrición, enfermedad por reflujo gastroesofágico y microaspiración

\begin{tabular}{|c|c|c|}
\hline \multicolumn{2}{|r|}{ Evidencia/Recomendación } & Nivel/Grado \\
\hline$E$ & $\begin{array}{l}\text { - El estado nutricional adecuado a los } \\
\text { dos años de edad es un predictor } \\
\text { positivo de resultados pulmonares } \\
\text { en la infancia } \\
\text { - El aumento de peso hospitalario } \\
\text { tiene un efecto significativo e } \\
\text { independiente en los resultados del } \\
\text { desarrollo neurológico } \\
\text { - Los bebés con DBP tienen un gasto } \\
\text { energético aumentado hasta en un } \\
25 \% \text { por encima del valor calórico } \\
\text { total }\end{array}$ & $\begin{array}{c}\mathrm{lb} \\
\text { Shekelle } \\
\text { Poindexter BB, } \\
2015\end{array}$ \\
\hline $\mathrm{R}$ & $\begin{array}{l}\text { Las necesidades de energía para un } \\
\text { lactante con DBP se han estimado } \\
\text { entre } 140 \text { a } 150 \mathrm{kcal} / \mathrm{kg} / \text { día. }\end{array}$ & $\begin{array}{c}\text { A } \\
\text { Shekelle } \\
\text { Poindexter BB, } \\
2015\end{array}$ \\
\hline$E$ & $\begin{array}{l}\text { Existe asociación entre crecimiento } \\
\text { lineal y mejores resultados cognitivos a } \\
\text { los dos años de edad }\end{array}$ & $\begin{array}{c}\mathrm{lb} \\
\text { Shekelle } \\
\text { Poindexter BB, } \\
2015\end{array}$ \\
\hline $\mathrm{R}$ & $\begin{array}{l}\text { En los niños con DBP es necesario } \\
\text { evaluar incremento en peso, longitud y } \\
\text { perímetro cefálico }\end{array}$ & $\begin{array}{c}\text { A } \\
\text { Shekelle } \\
\text { Poindexter BB, } \\
2015\end{array}$ \\
\hline$\checkmark$ & $\begin{array}{l}\text { Evaluar el crecimiento lineal a través } \\
\text { de la medición longitud para la edad o } \\
\text { talla para la edad } \\
\text { - La medición de la longitud se realiza } \\
\text { acostado hasta la edad de un año } \\
11 \text { meses y } 29 \text { días } \\
\text { - La medición de la talla desde los } \\
\text { dos años }\end{array}$ & $\begin{array}{l}\text { Punto de buena } \\
\text { práctica }\end{array}$ \\
\hline$E$ & $\begin{array}{l}\text { Los niños con DBP pueden tener un } \\
\text { aporte nutricional bajo debido a: } \\
\text { - Restricción de líquidos, disfagia, } \\
\text { fatiga durante la alimentación o } \\
\text { reflujo } \\
\text { - Metilxantinas y beta } 2 \text { agonistas que } \\
\text { pueden aumentar el consumo de } \\
\text { energía } \\
\text { - El uso de esteroides sistémicos que } \\
\text { pueden interferir con el crecimiento } \\
\text { La falla de crecimiento varía de } 30 \text { a } \\
67 \% \text { posterior a su egreso de la unidad } \\
\text { de cuidados neonatales } \\
\text { Los niños con DBP tienen déficits en } \\
\text { masa libre de grasa y grasa corporal total } \\
\text { que persiste hasta el primer año de vida }\end{array}$ & $\begin{array}{c}\mathrm{lb} \\
\text { Shekelle } \\
\text { Poindexter BB, } \\
2015\end{array}$ \\
\hline$E$ & $\begin{array}{l}\text { La DBP predispone a los } \\
\text { sobrevivientes a morbilidades }\end{array}$ & $\begin{array}{c}\mathrm{lb} \\
\text { Shekelle }\end{array}$ \\
\hline
\end{tabular}


- Deben incluirse en un programa de estimulación temprana

- Deben integrarse a un programa de seguimiento neurológico multidisciplinario (pediatra, rehabilitador físico, psicopedagogo, fisioterapeuta neurólogo pediatra, psicólogo, otorrinolaringólogo, oftalmólogo, foniatra y trabajador social)

- El seguimiento debe ser a largo plazo (adolescencia y adultez)

perímetro cefálico de forma regular

3. Modificar la dieta para alcanzar los objetivos de crecimiento según sea necesario

4. La fórmula suplementada con fortificadores ha demostrado mejoría nutricional

5. Si el crecimiento es pobre:

- Considere aumentar la densidad calórica de la dieta

- Descartar enfermedad significativa por reflujo gastroesofágico, aversión oral o aspiración

- Descartar hipoxia no diagnosticada.

- Algunos pacientes necesitaran gastrostomía y/o funduplicatura, de acuerdo a una evaluación multidisciplinaria

Neurológico

\begin{tabular}{|c|c|c|}
\hline & Evidencia/Recomendación & Nivel/Grado \\
\hline$E$ & $\begin{array}{l}\text { La DBP aumenta significativamente el } \\
\text { riesgo de deterioro del neurodesarrollo } \\
\text { en los recién nacidos prematuros; se } \\
\text { asocia con bajos puntajes del índice } \\
\text { de desarrollo mental y psicomotor en la } \\
\text { Escala Bayley } \\
\text { Los resultados adversos del } \\
\text { neurodesarrollo como la parálisis } \\
\text { cerebral, deficiencia mental y } \\
\text { psicomotora, el déficit visual y de } \\
\text { audición son mayores en los lactantes } \\
\text { con DBP } \\
\text { Los déficits cognitivos, motores y } \\
\text { conductuales son más comunes } \\
\text { en niños en edad escolar con } \\
\text { antecedentes de DBP }\end{array}$ & $\begin{array}{c}\text { lb } \\
\text { Shekelle } \\
\text { Jain D, } \\
2014 \\
\text { Jensen EA, } \\
2014\end{array}$ \\
\hline$E$ & $\begin{array}{l}\text { Los bebés con peso al nacer }<1.500 \\
\text { g con DBP tienen mayor retraso } \\
\text { del lenguaje y un aumento de la } \\
\text { discapacidad motora fina y gruesa }\end{array}$ & $\begin{array}{c}\text { la } \\
\text { Shekelle } \\
\text { DynaMed Plus, } \\
2017\end{array}$ \\
\hline$\checkmark$ & $\begin{array}{l}\text { Todos los niños con diagnóstico de } \\
\text { DBP: }\end{array}$ & $\begin{array}{l}\text { Punto de buena } \\
\text { práctica }\end{array}$ \\
\hline
\end{tabular}

Medidas preventivas

\begin{tabular}{|c|c|c|}
\hline & Evidencia/Recomendación & Nivel/Grado \\
\hline$E$ & $\begin{array}{l}\text { En relación con los factores } \\
\text { medioambientales, cabe destacar } \\
\text { que la asistencia a la guardería, } \\
\text { el tabaquismo domiciliario y el } \\
\text { hacinamiento se han asociado con } \\
\text { mayor riesgo de infección respiratoria } \\
\text { aguda en los menores de dos años }\end{array}$ & $\begin{array}{c}\text { lb } \\
\text { Shekelle } \\
\text { Giubergia V, } \\
2013\end{array}$ \\
\hline$E$ & $\begin{array}{l}\text { Las influencias ambientales, como el } \\
\text { humo de tabaco, pueden contribuir a la } \\
\text { obstrucción del flujo aéreo }\end{array}$ & $\begin{array}{c}\text { la } \\
\text { Shekelle } \\
\text { El Mazloum D, } \\
2014\end{array}$ \\
\hline $\mathrm{R}$ & $\begin{array}{l}\text { Evitar la asistencia a la guardería } \\
\text { Informar a la familia sobre el riesgo de } \\
\text { la exposición al humo de tabaco } \\
\text { Gestionar la mejora de la condición de } \\
\text { vivienda en las familias de niños con } \\
\text { DBP en situación de vulnerabilidad }\end{array}$ & $\begin{array}{c}\text { A } \\
\text { Shekelle } \\
\text { Giubergia V, } \\
2013\end{array}$ \\
\hline$\checkmark$ & $\begin{array}{l}\text { - Evitar cambios bruscos de } \\
\text { - Evitar asistencia a lugares concurridos } \\
\text { (cine, iglesia, fiestas, etcétera) } \\
\text { - Evitar contacto con personas } \\
\text { enfermas de infecciones } \\
\text { respiratorias } \\
\text { - No deben existir aves en el domicilio } \\
\text { del paciente } \\
\text { - Se debe realizar lavado de manos } \\
\text { frecuente } \\
\text { - Iniciar esquema de vacunación en } \\
\text { los primeros dos meses de vida del } \\
\text { paciente } \\
\text { - Los lactantes con DBP deben recibir } \\
\text { un esquema igual al recién nacido de } \\
\text { término, siguiendo los lineamientos } \\
\text { aceptados universalmente y de acuerdo } \\
\text { al esquema nacional de vacunación } \\
\text { El cuidador y los hermanos del } \\
\text { paciente deben tener esquema de } \\
\text { vacunación completo con énfasis en } \\
\text { los refuerzos de vacunación contra } \\
\text { influenza }\end{array}$ & $\begin{array}{c}\text { Punto de buena } \\
\text { práctica }\end{array}$ \\
\hline
\end{tabular}


Criterios de referencia y contrarreferencia

\begin{tabular}{|c|c|c|}
\hline & Evidencia/Recomendación & Nivel/Grado \\
\hline$\checkmark$ & $\begin{array}{l}\text { Criterios de referencia a segundo nivel } \\
\text { de atención Se debe referir a todo } \\
\text { paciente que cumpla con los criterios } \\
\text { diagnósticos de DBP }\end{array}$ & $\begin{array}{c}\text { Punto de buena } \\
\text { práctica }\end{array}$ \\
\hline$\checkmark$ & $\begin{array}{l}\text { Criterios de referencia de segundo a } \\
\text { tercer nivel de atención } \\
\text { Paciente que cumpla con los criterios } \\
\text { diagnósticos de DBP más alguno de los } \\
\text { siguientes: } \\
\text { - Requiera oxígeno suplementario. } \\
\text { - Presente cuadros recurrentes de } \\
\text { sibilancias, estridor o tos } \\
\text { - Detención pondoestatural a pesar de } \\
\text { alimentación apropiada } \\
\text { - Haya sido catalogado como DBP } \\
\text { moderada o severa } \\
\text { - Presente HP, desnutrición, } \\
\text { cardiopatía, nefropatía, edema } \\
\text { agudo pulmonar o disfagia } \\
\text { En las unidades de segundo nivel } \\
\text { que no cuenten con la infraestructura } \\
\text { suficiente para el cumplimiento de } \\
\text { las recomendaciones de la presente } \\
\text { guía deberán, en los términos de la } \\
\text { regionalización de los servicios y los } \\
\text { lineamientos delegacionales en la materia, } \\
\text { referir al paciente para su atención a otra } \\
\text { unidad de mayor capacidad resolutiva }\end{array}$ & $\begin{array}{c}\text { Punto de buena } \\
\text { práctica }\end{array}$ \\
\hline$\checkmark$ & $\begin{array}{l}\text { Criterios de contrarreferencia de tercer } \\
\text { a segundo nivel de atención } \\
\text { Se envía a segundo nivel de atención } \\
\text { para seguimiento a largo plazo con } \\
\text { indicaciones terapéuticas. De ser } \\
\text { necesario se establece temporalidad } \\
\text { para revaloración del caso } \\
\text { Se referirá de tercer a segundo nivel de } \\
\text { atención a los pacientes que: } \\
\text { - Hayan alcanzado la estabilidad } \\
\text { clínica, en fase de continuación o } \\
\text { mantenimiento } \\
\text { - Con máximo beneficio al tratamiento }\end{array}$ & $\begin{array}{c}\text { Punto de buena } \\
\text { práctica }\end{array}$ \\
\hline$\checkmark$ & $\begin{array}{l}\text { Criterios de contrarreferencia de } \\
\text { segundo a primer nivel de atención } \\
\text { Se envía a primer nivel de atención } \\
\text { para seguimiento a largo plazo con } \\
\text { indicaciones terapéuticas. De ser } \\
\text { necesario se establece temporalidad } \\
\text { para revaloración del caso } \\
\text { Se referirá del segundo a primer nivel } \\
\text { de atención a los pacientes que: } \\
\text { - En quienes haya remitido la } \\
\text { sintomatología y se encuentren } \\
\text { en fase de continuación o } \\
\text { mantenimiento } \\
\text { - Con máximo beneficio al tratamiento }\end{array}$ & $\begin{array}{c}\text { Punto de buena } \\
\text { práctica }\end{array}$ \\
\hline
\end{tabular}

\section{ANEXOS}

\subsection{Estrategia de búsqueda}

\subsubsection{Primera etapa}

Esta primera etapa consistió en buscar documentos relacionados al tema displasia broncopulmonar en PubMed. La búsqueda se limitó a estudios en humanos, documentos publicados durante los últimos cinco años en idioma inglés y español, del tipo de documento de Guías de Práctica Clínica, metaanálisis, revisiones sistemáticas y ensayos controlados aleatorizados. Además, se utilizaron los siguientes términos validados del MeSh «classification, complications, diagnosis, diagnostic imaging, diet therapy, drug therapy, rehabilitation, therapy». Esta etapa de la estrategia de búsqueda arrojó 190 resultados, de los cuales se utilizaron 31 documentos en la elaboración de la guía.

\begin{tabular}{l|c|}
\hline \multicolumn{1}{|c|}{ Búsqueda } & Resultado \\
\hline ("Bronchopulmonary Dysplasia/classification"[Mesh] & 190 \\
\cline { 2 - 2 } OR "Bronchopulmonary Dysplasia/ & Utilizados \\
complications"[Mesh] OR "Bronchopulmonary & \\
Dysplasia/diagnosis"[Mesh] OR "Bronchopulmonary & \\
Dysplasia/diagnostic imaging"[Mesh] OR & 31 \\
"Bronchopulmonary Dysplasia/prevention and & \\
control"[Mesh] OR "Bronchopulmonary Dysplasia/ & \\
rehabilitation"[Mesh] OR "Bronchopulmonary & \\
Dysplasia/therapy"[Mesh]) AND ((Guideline[ptyp] & \\
OR Meta-Analysis[ptyp] OR Practice & \\
Guideline[ptyp] OR Randomized Controlled & \\
Trial[ptyp] OR Review[ptyp] OR systematic[sb]) & \\
AND "loattrfull text"[sb] AND "2013/01/12"[PDAT] & \\
:"2018/01/10"[PDAT] AND ("humans"[MeSH & \\
Terms] AND (English[lang] OR Spanish[lang]) AND & \\
("infant"[MeSH Terms] OR "child"[MeSH Terms] OR & \\
"adolescent"[MeSH Terms])) & \\
\hline
\end{tabular}

\subsubsection{Segunda etapa}

En esta segunda etapa consistió en buscar documentos relacionados al tema displasia broncopulmonar en LILACS (en BVS). La búsqueda se limitó a estudios en humanos, documentos publicados durante los últimos 10 años (búsqueda extendida), en idioma inglés, portugués y español, del tipo de documento de Guías de Práctica Clínica, revisiones sistemáticas y ensayos controlados aleatorizados. Además, se utilizaron los siguientes términos «prognosis, etiology, diagnosis, therapy, prediction». Esta etapa de la estrategia de búsqueda arrojó tres resultados, de los cuales no se utilizaron documentos en la elaboración de la guía; debido a que el resultado estaba enfocado 
a la etapa perinatal o ya se encontraban incluidos en la búsqueda de Pubmed.

\begin{tabular}{|l|c|}
\hline \multicolumn{1}{|c|}{ Búsqueda } & Resultado \\
\hline bronchopulmonary dysplasia AND & 3 \\
(instance:"regional") AND ( db:("LILACS") & Utilizados \\
AND mi:("Displasia Broncopulmonar") AND & 0 \\
type_of_study:("clinical_trials" OR "guideline" & \\
OR "systematic_reviews") AND clinical__ & \\
aspect:("prognosis" OR "etiology" OR "diagnosis" OR & \\
"therapy" OR "prediction") AND limit:("hu mans")) & \\
\hline
\end{tabular}

\subsubsection{Tercera etapa}

Esta tercera etapa consistió en buscar documentos relacionados al tema displasia broncopulmonar en TRIP DATABASE. Se realizaron dos búsquedas, ya que se detectó que en esta base de datos se utilizaban como sinónimos el término "«bronchopulmonary displasia» con «chronic neonatal lung disease». La búsqueda se limitó a documentos publicados durante los últimos 10 años (búsqueda extendida) en idioma inglés y español, del tipo de documento de Guías de Práctica Clínica y revisiones sistemáticas. Esta etapa de la estrategia de búsqueda, la primera búsqueda arrojó 31 resultados, de los cuales se utilizó dos documentos en la elaboración de la guía, el resto se descartaron porque ya se encontraban dentro de la búsqueda de PubMed. En la segunda búsqueda se obtuvieron tres resultados de los cuales se utilizó 1, ya los otros artículos estaban enfocados en bronquiolitis y/o tenían información repetida.

\begin{tabular}{|l|c|}
\hline Búsqueda & Resultado \\
\hline "Bronchopulmonary Dysplasia" & 34 \\
\hline "Chronic neonatal lung disease" & Utilizados \\
Systematic Reviews or Guideline & 3 \\
Desde 2013 al 26/01/2018 & \\
\hline
\end{tabular}

\subsubsection{Cuarta etapa}

Esta cuarta etapa consistió en buscar documentos relacionados al tema displasia broncopulmonar en CONRICYT. La búsqueda se limitó a estudios en humanos, documentos publicados durante los últimos cinco años en idioma inglés y español, del tipo de documento de Guías de Práctica Clínica, metaanálisis, revisiones sistemáticas y ensayos controlados aleatorizados. Además, se utilizaron los siguientes sub encabezamientos o calificadores: «classification, complications, diagnosis, diagnostic imaging, diet therapy, drug therapy, rehabilitation, therapy». Esta etapa de la estrategia de búsqueda arrojó 25 resultados, de los cuales se utilizó dos documentos en la elaboración de la guía; el resto no se utilizaron debido a que estaban enfocadas a los cuidados perinatales o ya se encontraban dentro de la búsqueda de PubMed.

\begin{tabular}{l|c}
\hline \multicolumn{1}{c|}{ Búsqueda } & Resultado \\
\hline ((TitleCombined:(Bronchopulmonary Dysplasia/ & 25 \\
\cline { 2 - 2 } classification)) OR (TitleCombined:(Bronchopulmon & Utilizados \\
ary Dysplasia/complications)) OR (TitleCombined:( & 2 \\
Bronchopulmonary Dysplasia/diagnosis)) OR (Title & \\
Combined:(Bronchopulmonary Dysplasia/diagnostic & \\
imaging)) OR (TitleCombined:(Bronchopulmonary & \\
Dysplasia/diet therapy)) OR (TitleCombined:(Bron & \\
chopulmonary Dysplasia/drug therapy)) OR (TitleC & \\
ombined:(Bronchopulmonary Dysplasia/prevention & \\
and control)) OR (TitleCombined:(Bronchopulmonary & \\
Dysplasia/rehabilitation)) OR (TitleCombined:(Bronc & \\
hopulmonary Dysplasia/therapy))) AND ((Guideline) & \\
OR (Meta-Analysis) OR (Randomized Controlled & \\
Trial) OR (Practice Guideline) OR (Review) OR & \\
(Systematic Reviews) OR (Humans)) & \\
FECHA DE BÚSQUEDA 26/O1/2018 17:00 HRS & \\
TEXTO COMPLETO EN LÍNEA, ÚLTIMOS CINCO & \\
AÑOS, INGLESY ESPAÑOL & \\
\hline
\end{tabular}

FORMATO PARA CONTROL DE FUENTES DOCUMENTALES

\begin{tabular}{|c|c|c|c|c|c|}
\hline \multirow[b]{2}{*}{ 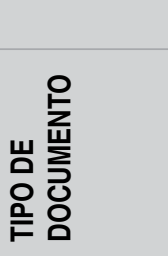 } & \multicolumn{5}{|c|}{ BASE DE DATOS } \\
\hline & $\begin{array}{l}\text { 岂 } \\
\text { 产 }\end{array}$ & $\frac{5}{\frac{5}{0}}$ & 导 & 蓆 & 迹 \\
\hline $\begin{array}{l}\text { Guías de } \\
\text { Práctica } \\
\text { Clínica }\end{array}$ & 0 & 0 & 0 & 1 & 1 \\
\hline Metaanálisis & 2 & 0 & 0 & 0 & 2 \\
\hline $\begin{array}{l}\text { Revisiones } \\
\text { sistemáticas }\end{array}$ & 4 & 0 & 0 & 0 & 4 \\
\hline $\begin{array}{l}\text { Ensayos } \\
\text { controlados } \\
\text { aleatorizados }\end{array}$ & 0 & 0 & 0 & 0 & 0 \\
\hline Revisiones & 25 & 2 & 0 & 2 & 29 \\
\hline Total & 31 & 2 & 0 & 3 & 36 \\
\hline
\end{tabular}

\section{Algoritmo de búsqueda en pubmed}

1. Bronchopulmonary Dysplasia $[\mathrm{MeSH}]$

2. Classification [SubHeading]

3. Complications [SubHeading]

4. Diagnosis [SubHeading]

5. Diagnostic imaging [SubHeading]

6. Prevention and control [SubHeading]

7. Rehabilitation [SubHeading] 
8. Therapy [SubHeading]

9. \#2 OR \#3 OR \#4 OR \#5 OR \#6 OR \#7 OR \#8

10. \#1 AND \#9

11. Guideline[ptyp]

12. Meta-Analysis[ptyp]

13. Practice Guideline[ptyp]

14. Randomized Controlled Trial[ptyp]

15. Review[ptyp]

16. systematic[sb])

17. \#11 OR \#12 OR \#13 OR \#14 OR \#15 OR \#16

18. \#10 AND \#17

19. "loattrfull text"[sb]

20. \#18 AND \#19

21. "2013/01/12"[PDAT] : "2018/01/10"[PDAT]

22. \#20 AND \#21

23. "humans"[MeSH Terms])

24. \#22 AND \#23

25. English[lang]

26. Spanish[lang])

27. \#25 OR \#26

28. \#24 AND \#27

29. "infant"[MeSH Terms]

30. "child"[MeSH Terms]

31. "adolescent"[MeSH Terms]

32. \#29 OR \#30 OR \#31

33. \#28 AND \#32

34. \#1 AND (\#2 OR \#3 OR \#4 OR \#5 OR \#6 OR \#7 OR \#8) AND (\#11 OR \#12 OR \#13 OR \#14 OR \#15 OR \#16) AND \#19 AND \#21 AND \#23 AND (\#25 OR \#26) AND (\#29 OR \#30 OR \#31)

\subsection{Seguimiento del paciente con displasia broncopulmonar}

\subsubsection{Citas de seguimiento recomendado en el paciente con DBP}

\begin{tabular}{|l|l|}
\hline Primer cita: & $\begin{array}{l}\text { - A las dos semanas después del alta, o } \\
\text { a las 40 semanas de edad gestacional } \\
\text { corregida, según fecha de alta de } \\
\text { Neonatología. }\end{array}$ \\
\hline $\begin{array}{l}\text { Citas subsecuentes } \\
\text { durante los } \\
\text { primeros doce } \\
\text { meses de vida }\end{array}$ & $\begin{array}{l}\text { - Cada 1-3 meses según las } \\
\text { necesidades del paciente } \\
\text { (oxigenoterapia, traqueostomía, } \\
\text { diuréticos, etcétera). }\end{array}$ \\
\hline $\begin{array}{l}\text { Citas subsecuentes } \\
\text { de los 12 a los 24 } \\
\text { meses de vida }\end{array}$ & $\begin{array}{l}\text { - Cada 3-6 meses. } \\
\text { - Si la evolución no es favorable: visitas } \\
\text { según necesidades. }\end{array}$ \\
\hline $\begin{array}{l}\text { Citas subsecuentes } \\
\text { partir de los 24 } \\
\text { meses }\end{array}$ & $\begin{array}{l}\text { - Si la evolución es favorable: visita anual } \\
\text { hasta los 15 años 11 meses 29 días. }\end{array}$ \\
& $\begin{array}{l}\text { Si la evolución no es favorable: visitas } \\
\text { según necesidades. }\end{array}$ \\
\hline
\end{tabular}

\begin{tabular}{|c|c|}
\hline $\begin{array}{l}\text { A partir de los } 15 \\
\text { años } 11 \text { meses } 29 \\
\text { días (según cada } \\
\text { centro): }\end{array}$ & $\begin{array}{l}\text { Transición a Neumología de Adultos, } \\
\text { especialmente en casos de DBP } \\
\text { moderada-grave. }\end{array}$ \\
\hline
\end{tabular}

Adaptado de: Pérez TS, Rueda ES, Alfonso DJ, et al. Protocolo de seguimiento de los pacientes con displasia broncopulmonar. An Pediatr (Barc). 2016;84(1):61.e161.e9. http://dx.doi.org/10.1016/j.anpedi.2015.04.020.

\subsubsection{Controles ambulatorios de los pacientes con displasia broncopulmonar}

\begin{tabular}{|c|c|c|c|c|}
\hline Actividades & 1a. cita & $\begin{array}{l}\text { Citas } \\
\text { 1er año }\end{array}$ & $\begin{array}{c}\text { Citas } \\
2-5 \\
\text { años }\end{array}$ & $\begin{array}{l}\text { Citas } \\
6-18 \\
\text { años }\end{array}$ \\
\hline $\begin{array}{l}\text { Informar al cuidador } \\
\text { sobre la DBP y } \\
\text { pronóstico a largo } \\
\text { plazo. }\end{array}$ & $\checkmark$ & $\checkmark$ & $\checkmark$ & $\checkmark$ \\
\hline $\begin{array}{l}\text { Actualizar y aclarar } \\
\text { dudas. }\end{array}$ & $\checkmark$ & $\checkmark$ & $\checkmark$ & $\checkmark$ \\
\hline $\begin{array}{l}\text { Prevención de } \\
\text { infecciones } \\
\text { respiratorias y } \\
\text { medidas frente al } \\
\text { tabaquismo pasivo. }\end{array}$ & $\checkmark$ & $\checkmark$ & $\checkmark$ & $\checkmark$ \\
\hline $\begin{array}{l}\text { Antecedentes } \\
\text { familiares de atopia } \\
\text { o enfermedades } \\
\text { pulmonares. }\end{array}$ & $\checkmark$ & & & \\
\hline $\begin{array}{l}\text { Contaminación } \\
\text { ambiental } \\
\text { (tabaquismo, aves, } \\
\text { biomasa). }\end{array}$ & $\checkmark$ & $\checkmark$ & $\checkmark$ & $\checkmark$ \\
\hline $\begin{array}{l}\text { Curva de crecimiento } \\
\text { (indicador de buena } \\
\text { evolución). }\end{array}$ & $\checkmark$ & $\checkmark$ & $\checkmark$ & $\checkmark$ \\
\hline $\begin{array}{l}\text { Alimentación: } \\
\text { - Volumen. } \\
\text { - Tos durante } \\
\text { - alimentación. } \\
\text { - Atragantamiento. } \\
\text { - Disnea. } \\
\text { - Estridor. } \\
\text { - Ronquido. } \\
\text { - Apnea. } \\
\text { - Cianosis. } \\
\text { - Regurgitación. } \\
\text { - Vómito. }\end{array}$ & $\checkmark$ & $\checkmark$ & & \\
\hline $\begin{array}{l}\text { Tomar } \mathrm{SpO}_{2} \text { al aire } \\
\text { ambiente y con } \\
\text { oxígeno suplementario } \\
\text { si lo utiliza. }\end{array}$ & $\checkmark$ & $\checkmark$ & $\checkmark$ & $\checkmark$ \\
\hline
\end{tabular}




\begin{tabular}{|c|c|c|c|c|}
\hline $\begin{array}{l}\text { Interrogar sobre } \\
\text { visitas a urgencias e } \\
\text { ingresos hospitalarios } \\
\text { por problemas } \\
\text { respiratorios }\end{array}$ & $\checkmark$ & $\checkmark$ & $\checkmark$ & $\checkmark$ \\
\hline $\begin{array}{l}\text { Presencia de } \\
\text { sibilancias } \\
\text { recurrentes. }\end{array}$ & $\checkmark$ & $\checkmark$ & $\checkmark$ & $\checkmark$ \\
\hline $\begin{array}{l}\text { Supervisión y ajuste } \\
\text { de tratamiento } \\
\text { farmacológico. }\end{array}$ & $\checkmark$ & $\checkmark$ & $\checkmark$ & \\
\hline Palivizumab & $\checkmark^{*}$ & $\checkmark^{*}$ & & \\
\hline Verificar vacunación. & $\checkmark$ & $\checkmark$ & $\checkmark$ & $\checkmark$ \\
\hline $\begin{array}{l}\text { Evaluación } \\
\text { cardiológica y cribado } \\
\text { HP en todos los niños } \\
\text { con DBP. }\end{array}$ & $\checkmark$ & $\checkmark$ & & \\
\hline $\begin{array}{l}\text { Estudios de } \\
\text { imagen: Radiografía } \\
\text { posteroanterior } \\
\text { durante el } \\
\text { primer año de } \\
\text { vida. En caso } \\
\text { de comorbilidad } \\
\text { individualizar en } \\
\text { cada paciente. }\end{array}$ & $\checkmark$ & $\checkmark$ & & \\
\hline $\begin{array}{l}\text { Valorar TCAR } \\
\text { pulmonar, } \\
\text { gammagrafía. } \\
\text { Sólo DBP } \\
\text { moderada-grave } \\
\text { con comorbilidad } \\
\text { y persistencia o } \\
\text { empeoramiento } \\
\text { de síntomas } \\
\text { respiratorios } \\
\text { (neumólogo } \\
\text { pediatra). }\end{array}$ & & $\checkmark$ & $\checkmark$ & \\
\hline $\begin{array}{l}\text { Pruebas de función } \\
\text { pulmonar, de } \\
\text { acuerdo a estado } \\
\text { clínico (valoración } \\
\text { por neumología } \\
\text { pediátrica). }\end{array}$ & & $\begin{array}{l}\checkmark \\
\dagger\end{array}$ & $\begin{array}{l}\checkmark \\
\dagger\end{array}$ & $\begin{array}{l}\checkmark \\
\dagger\end{array}$ \\
\hline $\begin{array}{l}\text { Electrolitos séricos } \\
\text { si el paciente recibe } \\
\text { diuréticos y/o } \\
\text { presenta edema. }\end{array}$ & $\checkmark$ & $\checkmark$ & & \\
\hline $\begin{array}{l}\text { Valorar } \\
\text { polisomnografía: } \\
\text { Apneas, SAHOS. } \\
\text { Retiro de oxígeno } \\
\text { (si se encuentra } \\
\text { disponible) }\end{array}$ & $\checkmark$ & $\checkmark$ & $\checkmark$ & \\
\hline
\end{tabular}

\begin{tabular}{|l|l|l|l|l|}
\hline Serie esofago- & $\checkmark$ & $\checkmark$ & & \\
gastroduodenal & & & & \\
con mecánica de & & & & \\
deglución (paciente & & & \\
con síntomas de & & & \\
aspiración a vía & & & \\
aérea ${ }^{\ddagger}$ ). & & & & \\
\hline
\end{tabular}

*Se recomienda administrar Palivizumab en niños menores de 1 año de preferencia, antes de que cumplan los 6 meses de edad, debido a que tienen mayor riesgo de desarrollar enfermedad grave por virus sincitial respiratorio.

† De acuerdo a la edad y condición clínica se valorara: Babypletismografía (edad < 2 años y < 10kg); pletismografía por dilución con helio de los 2-5 años; oscilometría impulso > 3 años; espirometría $>5$ años.

¥Tos durante la alimentación; eventos de atragantamiento; mayor de 30 minutos de duración por toma de alimento; sialorrea; estertores asociados a la toma de alimentos.

\subsection{Cuantificación de líquidos}

Para estimar la producción de leche materna puede realizarse:

a) A través de la extracción de leche y cuantificarla.

b) Pesando al niño antes y después de lactar, se considera $1 \mathrm{~g}=1$ $\mathrm{mL}$ y al menos ocho tetadas diarias

Lactante prematuro que ha alcanzado $1,900 \mathrm{~g}$ de peso se pesa pretetada $=1,900 \mathrm{~g}$ y después de amamantar Peso $=1,940 \mathrm{~g}$ (debe ser pesado en las mismas condiciones de vestimenta y en la misma balanza). Estos $40 \mathrm{~g}$ de diferencia se asumen como volumen lácteo producido en esa tetada y suponiendo ocho tetadas diarias resulta en $320 \mathrm{~mL}$ al día $(40 \times 8)$. Ese niño que pesa $1,900 \mathrm{~g}$ debería recibir 285 a $342 \mathrm{~mL}$ al día ( $1.9 \times 150=$ $285 ; 1.9 \times 180=342$ ); por lo tanto, la leche materna satisface su aporte de líquidos.

En caso de seno materno exclusivo: dar fortificadores (fortificación estándar, dirigida o personalizada), consultar Guía Mexicana de Lactancia Materna.

Para alimentación complementaria:

Utilizar una jeringa para medir el volumen (papillas).

Adaptado de: Ministerio de Salud. Guía Clínica Displasia Broncopulmonar del Prematuro. Santiago: MINSAL, 2009.

\subsection{Dosis bajas, medias y altas de corticosteroides inhalados en el menor de 5 años}

\begin{tabular}{|l|c|c|c|}
\hline & \multicolumn{3}{|c|}{ Dosis } \\
\hline \multicolumn{1}{|c|}{ Medicamento } & Baja & Media & Alta \\
\hline $\begin{array}{l}\text { Dipropionato de } \\
\text { beclometasona }\end{array}$ & $100-200$ & $>200-400$ & $>400$ \\
\hline Budesonida & $100-200$ & $>200-400$ & $>400$ \\
\hline Fluticasona & $50-100$ & $>100-200$ & $>200$ \\
\hline Mometasona & $50-100$ & $>100-200$ & $>200$ \\
\hline Ciclesonida & $50-100$ & $>100-200$ & $>200$ \\
\hline
\end{tabular}

Adaptado de: Larenas-Linnemann D, Salas-Hernández J, Vázquez-García JC, et al. Guía Mexicana del Asma 2017. Rev Alerg Mex 2017;64 Supl 1:s11-s128. 
Neumol Cir Torax. 2019; 78 (4): 371-394

\subsection{Diagrama de flujo protocolo retiro de oxígeno}

Protocolo retiro de oxígeno en los niños con displasia broncopulmonar

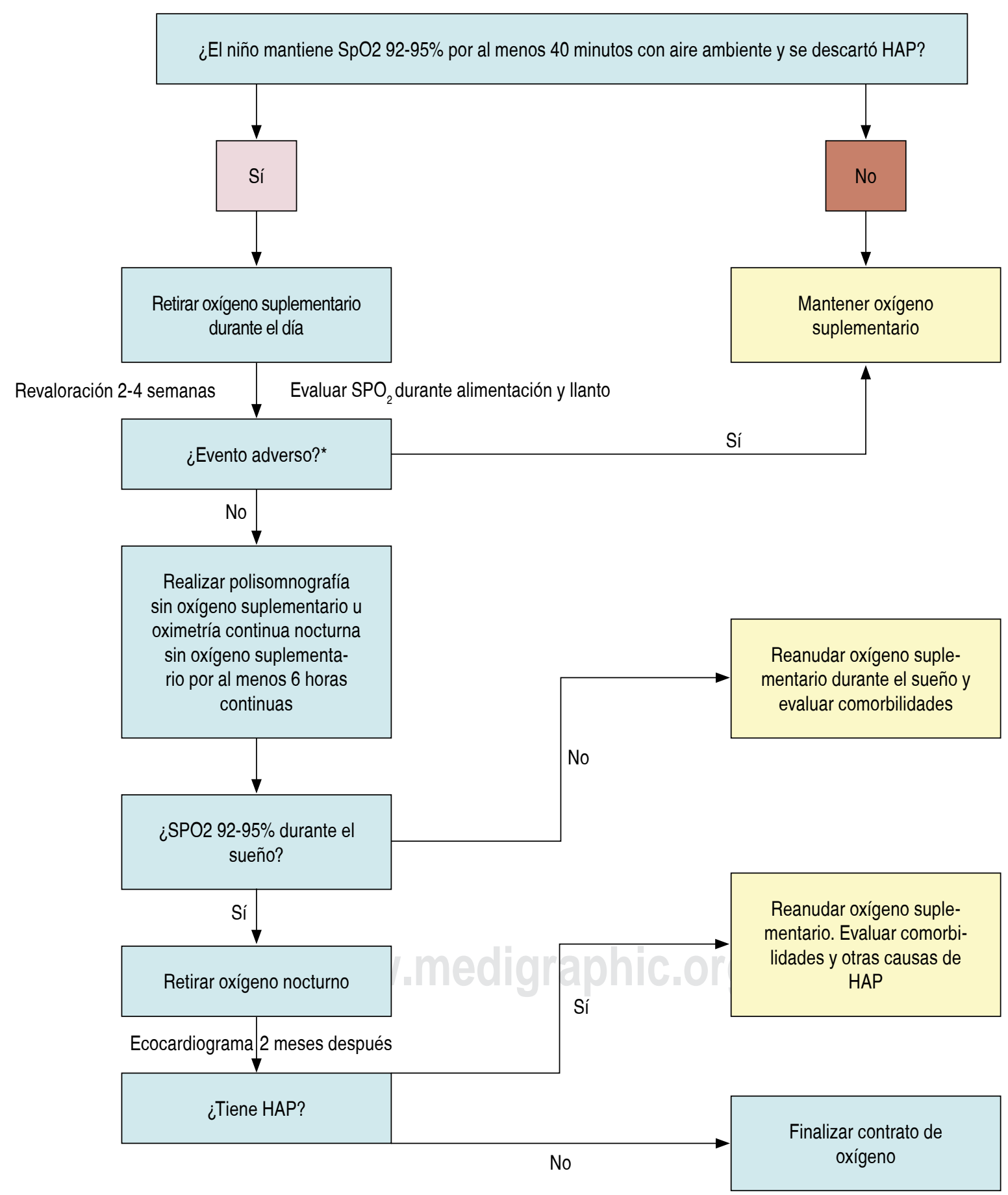

* Apnea, cianosis, dificultad respiratoria, desaturación o detención del crecimiento.

La administración de oxígeno, siempre debe ser otorgada a través de los dispositivos adecuados, como puntas nasales o mascarilla. 


\begin{tabular}{|l|l|}
\hline VD & Ventrículo derecho \\
\hline VSR & Virus sincicial respiratorio \\
\hline
\end{tabular}

\begin{tabular}{|c|c|}
\hline AHA & Asociación Americana del Corazón \\
\hline ATS & Asociación Americana del Tórax \\
\hline CPAP & Presión positiva continua en la vía aérea \\
\hline CTARVA & $\begin{array}{l}\text { Técnica de compresión toracoabdominal } \\
\text { rápida con volumen pulmonar aumentado }\end{array}$ \\
\hline DBP & Displasia broncopulmonar \\
\hline DLCO & Difusión pulmonar de monóxido de carbono \\
\hline EU & Estados Unidos de Norteamérica \\
\hline EG & Edad gestacional \\
\hline EPOC & Enfermedad pulmonar obstructiva crónica \\
\hline FEF & Flujo espiratorio forzado \\
\hline FEF 25-75 & $\begin{array}{l}\text { Flujo espiratorio forzado entre el } 25 \text { y el } 75 \% \\
\text { de la capacidad vital forzada }\end{array}$ \\
\hline $\mathrm{FEV}_{1} \circ \mathrm{VVEF}_{1}$ & $\begin{array}{l}\text { Volumen espiratorio forzado en el primer } \\
\text { segundo }\end{array}$ \\
\hline $\mathrm{FiO}_{2}$ & Fracción inspirada de oxígeno \\
\hline $\mathrm{HP}$ & Hipertensión pulmonar \\
\hline HP-DBP & $\begin{array}{l}\text { Hipertensión pulmonar asociada a displasia } \\
\text { broncopulmonar }\end{array}$ \\
\hline $\mathrm{IL}$ & Interleucina \\
\hline iNO & Óxido nítrico inhalado \\
\hline $\mathrm{kg}$ & Kilogramo \\
\hline $\mathrm{mg}$ & Miligramos \\
\hline$\mu g$ & Microgramos \\
\hline MSC & Células estromales mesenquimales \\
\hline $\mathrm{NICHD}$ & $\begin{array}{l}\text { Instituto Nacional de Salud Infantil y } \\
\text { Desarrollo Humano Eunice Kennedy Shriver }\end{array}$ \\
\hline NIS & Nationwide inpatient sample \\
\hline NO & Óxido nítrico \\
\hline PSAP & Presión sistólica de la arteria pulmonar \\
\hline RM & Resonancia magnética \\
\hline ROP & Retinopatía del prematuro \\
\hline RT & Regurgitación tricuspídea \\
\hline RVP & Resistencia vascular pulmonar \\
\hline SP-B & Proteína del surfactante B \\
\hline SP-C & Proteína del surfactante $\mathrm{C}$ \\
\hline $\mathrm{SpO}_{2}$ & Saturación percutánea de oxígeno \\
\hline TC & Tomografía computarizada \\
\hline Tc-99 & Tecnecio 99 \\
\hline TCAR & Tomografía computarizada de alta resolución \\
\hline UI & Unidades internacionales \\
\hline
\end{tabular}

\section{GLOSARIO}

\begin{tabular}{|c|c|}
\hline Crecimiento lineal & $\begin{array}{l}\text { Medición de la longitud para la edad o } \\
\text { talla para la edad. } \\
\text { - La medición de la longitud se realiza } \\
\text { acostado hasta el año } 11 \text { meses y } 29 \\
\text { días. } \\
\text { - La medición de la talla desde los dos } \\
\text { años. } \\
\text { Si por alguna causa es imposible medir } \\
\text { a un niño mayor de dos años parado, se } \\
\text { podrá medir acostado y para graficarlo } \\
\text { deberá restarse } 0.7 \mathrm{~cm} \text { de su talla. }\end{array}$ \\
\hline Ecocardiograma & $\begin{array}{l}\text { Es una técnica de imagen realizada con } \\
\text { ultrasonidos que permite valorar tanto la } \\
\text { anatomía, como la función cardíaca. }\end{array}$ \\
\hline $\begin{array}{l}\text { Exacerbación } \\
\text { de displasia } \\
\text { broncopulmonar }\end{array}$ & $\begin{array}{l}\text { Agravación o intensificación de los } \\
\text { síntomas. Es común entre los niños } \\
\text { con DBP menores de dos años; la } \\
\text { causa más frecuente está representada } \\
\text { por infecciones respiratorias. También } \\
\text { algunos factores ambientales como la } \\
\text { exposición a tabaco pueden contribuir al } \\
\text { deterioro agudo de estos pacientes. }\end{array}$ \\
\hline Oxigenoterapia & $\begin{array}{l}\text { Es el uso terapéutico de oxígeno con } \\
\text { la finalidad de aumentar el aporte de } \\
\text { oxígeno a los tejidos. }\end{array}$ \\
\hline Oxímetro & $\begin{array}{l}\text { Es un equipo que consiste en un dedal y } \\
\text { un aparato que grafica la saturación de } \\
\text { oxígeno en sangre. }\end{array}$ \\
\hline Polisomnografía & $\begin{array}{l}\text { Estudio que consiste en el registro } \\
\text { simultáneo de variables neurofisiológicas, } \\
\text { cardiorrespiratorias y de los eventos } \\
\text { cardíacos, neurológicos y motores que } \\
\text { acontecen durante el sueño y que pueden } \\
\text { afectar a la calidad del mismo. }\end{array}$ \\
\hline Prematurez & $\begin{array}{l}\text { Recién nacido que nace antes de } \\
\text { completar la semana } 37 \text { de gestación. }\end{array}$ \\
\hline Puntas nasales & $\begin{array}{l}\text { Es un tubo de plástico suave y flexible } \\
\text { con dos salidas que se introducen en los } \\
\text { orificios nasales. }\end{array}$ \\
\hline
\end{tabular}

\section{LECTURAS RECOMENDADAS}

1. Altit G, Dancea A, Renaud C, Perreault T, Lands LC, Sant'Anna G. Pathophysiology, screening and diagnosis of pulmonary hypertension in infants with bronchopulmonary dysplasia - A review of the literature. Paediatr Respir Rev 2017;23:16-26. doi: 10.1016/j. prrv.2016.11.002. 
Neumol Cir Torax. 2019; 78 (4): 371-394

2. Amin RS, Rutter MJ. Airway disease and management in bronchopulmonary dysplasia. Clin Perinatol 2015;42(4):857-870. doi: 10.1016/j.clp.2015.08.011.

3. Baker CD, Alvira CM. Disrupted lung development and bronchopulmonary dysplasia: opportunities for lung repair and regeneration. Curr Opin Pediatr 2014;26(3):306-314. doi: 10.1097/MOP.0000000000000095.

4. Barrington KJ, Fortin-Pellerin E, Pennaforte T. Fluid restriction for treatment of preterm infants with chronic lung disease. Cochrane Database Syst Rev 2017;2:CD005389. doi: 10.1002/14651858.CD005389.pub2.

5. Bates ML, Pillers D-AM, Palta M, Farrell ET, Eldridge MW. Ventilatory control in infants, children, and adults with bronchopulmonary dysplasia. Respir Physiol Neurobiol 2013;189(2):329-337. doi: 10.1016/j. resp.2013.07.015.

6. Berkelhamer SK, Mestan KK, Steinhorn RH. Pulmonary hypertension in bronchopulmonary dysplasia. Semin Perinatol 2013;37(2):124-131. doi: 10.1053/j.semperi.2013.01.009.

7. Bhandari A, Bhandari V. Biomarkers in bronchopulmonary dysplasia. Paediatr Respir Rev 2013;14(3):173-179. doi: 10.1016/j.prrv.2013.02.008.

8. Bhandari A, McGrath-Morrow S. Long-term pulmonary outcomes of patients with bronchopulmonary dysplasia. Semin Perinatol 2013;37(2):132-137. doi: 10.1053/j.semperi.2013.01.010.

9. Carraro S, Filippone M, Da Dalt L, et al. Bronchopulmonary dysplasia: The earliest and perhaps the longest lasting obstructive lung disease in humans. Early Hum Dev 2013;89(suppl 3):S3-S5. doi: 10.1016/j. earlhumdev.2013.07.015.

10. Clouse BJ, Jadcherla SR, Slaughter JL. Systematic review of inhaled bronchodilator and corticosteroid therapies in infants with bronchopulmonary dysplasia: Implications and future directions. PLOS One 2016; 11(2):e0148188. doi: 10.1371/journal.pone.0148188.

11. DynaMed Plus [Internet]. Ipswich (MA): EBSCO Information Services. 1995 - . Record No. 115226, Bronchopulmonary dysplasia; [updated 2017 Apr 28, cited 2018 jan 28]; [about 34 screens]. A vailable from http://www .dynamed.com/login.aspx? direct=true\&site=DynaMed\&id=115226.

12. El Mazloum D, Moschino L, Bozzetto S, Baraldi E. Chronic lung disease of prematurity: long-term respiratory outcome. Neonatology 2014;105(4):352-356. doi: 10.1159/000360651.

13. Thoracic Society of Australia and New Zealand; Fitzgerald DA, Massie $\mathrm{RJH}$, Nixon G, et al. Infants with chronic neonatal lung disease: recommendations for the use of home oxygen therapy. Med J Aust 2008;189(10):578-582.

14. Gawronski CA, Gawronski KM. Vitamin A supplementation for prevention of bronchopulmonary dysplasia: cornerstone of care or futile therapy? Ann Pharmacother 2016;50(8):680-684. doi: 10.1177/1060028016647066.

15. Ghanta S, Leeman KT, Christou H. An update on pharmacologic approaches to bronchopulmonary dysplasia. Semin Perinatol 2013;37(2):115-123. doi: 10.1053/j.semperi.2013.01.008.

16. Giubergia V, Rentería F. Seguimiento neumológico de los niños con displasia broncopulmonar al alta de la Unidad de Cuidados Intensivos Neonatal. Parte 2: Administración de oxígeno, tratamiento farmacológico y seguimiento. Arch Argent Pediatr 2013;111(3):252-258. http://dx.doi. org/10.5546/aap.2013.252.

17. Hartnett ME, Lane RH. Effects of oxygen on the development and severity of retinopathy of prematurity. J AAPOS 2013;17(3):229-234. doi: 10.1016/j. jaapos.2012.12.155.

18. Jain D, Bancalari E. Bronchopulmonary dysplasia: Clinical perspective. Birt Defects Res A Clin Mol Teratol 2014;100(3):134-144. doi: 10.1002/bdra.23229.

19. Jensen EA, Schmidt B. Epidemiology of bronchopulmonary dysplasia. Birt Defects Res A Clin Mol Teratol 2014;100(3):145-157. doi: 10.1002/ bdra.23235.

20. Jobe AH, Tibboel D. Update in pediatric lung disease 2013. Am J Respir Crit Care Med 2014;189(9):1031-1036. doi: 10.1164/rccm.2014020230UP.
21. Johnson AK, Lynch N, Newberry D, Jnah AJ. Impact of diuretic therapy in the treatment of bronchopulmonary dysplasia and acute kidney injury in the neonatal population. Adv Neonatal Care 2017;17(5):337-346. doi: 10.1097/ANC.0000000000000427.

22. Kotecha SJ, Edwards MO, Watkins WJ, Lowe J, Henderson AJ, Kotecha S. Effect of bronchodilators on forced expiratory volume in $1 \mathrm{~s}$ in pretermborn participants aged 5 and over: a systematic review. Neonatology 2015;107(3):231-240.

23. McEvoy CT, Aschner JL. The natural history of bronchopulmonary dysplasia: the case for primary prevention. Clin Perinatol 2015;42(4):911931. doi: 10.1016/j.clp.2015.08.014.

24. McEvoy CT, Jain L, Schmidt B, Abman S, Bancalari E, Aschner JL. Bronchopulmonary dysplasia: NHLBI workshop on the primary prevention of chronic lung diseases. Ann Am Thorac Soc 2014;11Suppl 3:S146-S153. doi: 10.1513/AnnalsATS.201312-424LD.

25. Mourani PM, Abman SH. Pulmonary vasculardisease in bronchopulmonary dysplasia: pulmonary hypertension and beyond. Curr 2013;25(3):329-337. doi: 10.1097/MOP.0b013e328360a3f6.

26. Nicolarsen J, Ivy D. Progress in the diagnosis and management of pulmonary hypertension in children. Curr Opin Pediatr 2014;26(5):527535. doi: 10.1097/MOP.0000000000000135.

27. Poindexter BB, Martin CR. Impact of nutrition on bronchopulmonary dysplasia. Clin Perinatol 2015;42(4):797-806. doi: 10.1016/j. clp.2015.08.007.

28. Ronkainen E, Dunder T, Peltoniemi O, Kaukola T, Marttila R, Hallman M. New BPD predicts lung function at school age: Follow-up study and meta-analysis. Pediatr Pulmonol 2015;50(11):1090-1098. doi: 10.1002/ ppul.23153.

29. Rosenfeld M, Allen J, Arets BH, et al.; American Thoracic Society Assembly on Pediatrics Working Group on Infant and Preschool Lung Function Testing. An Official American Thoracic Society workshop report: optimal lung function tests for monitoring cystic fibrosis, bronchopulmonary dysplasia, and recurrent wheezing in children less than 6 years of age. Ann Am Thorac Soc 2013;10(2):S1-S11. doi: 10.1513/ AnnalsATS.201301-017ST.

30. Rossor T, Greenough A. Advances in paediatric pulmonary vascular disease associated with bronchopulmonary dysplasia. Expert Rev Respir Med 2015;9(1):35-43. doi: 10.1586/17476348.2015.986470.

31. Sánchez LM, Moreno HJ, Botet MF, et al. Displasia broncopulmonar: definiciones y clasificación. An Pediatr (Barc) 2013;79(4):262.e1-262.e6. doi: 10.1016/j.anpedi.2013.02.003.

32. Strueby L, Thébaud B. Advances in bronchopulmonary dysplasia. Expert Rev Respir Med 2014;8(3):327-338. doi: 10.1586/17476348.2014.899907.

33. van Mastrigt $\mathrm{E}$, Logie $\mathrm{K}$, Ciet $\mathrm{P}$, et al. Lung CT imaging in patients with bronchopulmonary dysplasia: A systematic review. Pediatr Pulmonol 2016;51(9):975-986. doi: 10.1002/ppul.23446.

34. Walkup LL, Woods JC. Newer imaging techniques for bronchopulmonary dysplasia. Clin Perinatol 2015;42(4):871-187. doi: 10.1016/j. clp.2015.08.012.

35. Wardle AJ, Wardle R, LuytK, Tulloh R. The utility of sildenafil in pulmonary hypertension: a focus on bronchopulmonary dysplasia. Arch Dis Child 2013;98(8):613-617. doi: 10.1136/archdischild-2012-303333.

36. Zhang $\mathrm{H}$, Zhang J, Zhao S. Airway damage of prematurity: The impact of prolonged intubation, ventilation, and chronic lung disease. Semin Fetal Neonatal Med 2016;21(4):246-253. doi: 10.1016/j. siny.2016.04.001.

Conflicto de intereses: Los autores declaran no tener conflicto de intereses. 